\section{البصيرة: مبلة الصراهات الإهلامية AL-BASHIRAH: JOURNAL OF ISLAMIC STUIDES \\ Vol. 1 No. 1(2020): 160-179}

Website: https://journal.stiba.ac.id

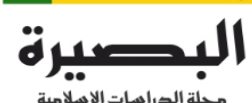

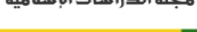

AL-BASHIRAH

\title{
الإمام مجد الدين أبو البركات عبد السلام ابن تيمية الحراني \\ وكتابه منتقى الأخبار
}

أحمد بن محمد بن عبد الهادي

الجامعة الإسلامية بالمدينة المنورة

البريد الإلكتروني:381001867@iu.edu.sa

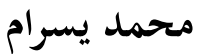 \\ المعهد العالي للدراسات الإسلامية واللغة العربية بمكسَّر \\ البريد الإلكتروني: yusrananshar@stiba.ac.id
}

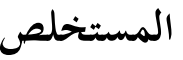

هذا البحث في التعريف بأحد أعلام الفقهاء والمحدثين، وهو بحد الدين أبو البركات عبد السلام ابن تيمية الحراني الحنبلي، والتعريف بكتابه

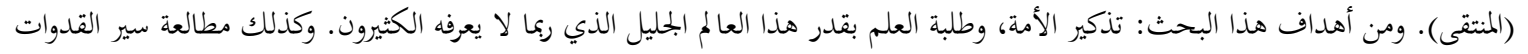

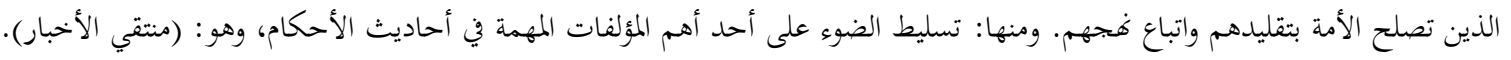

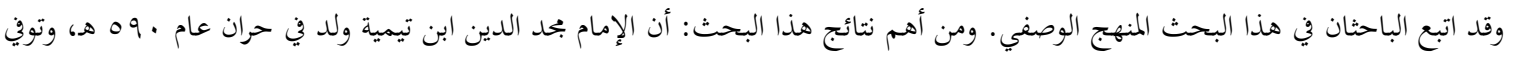

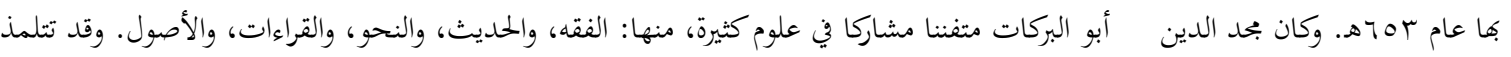

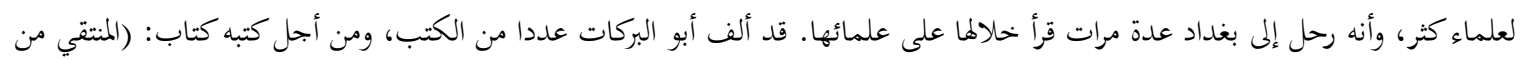

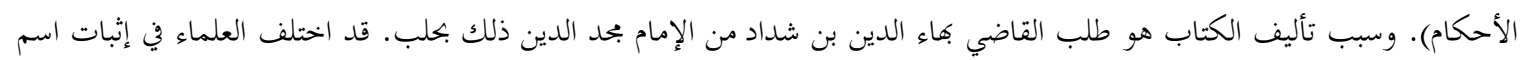

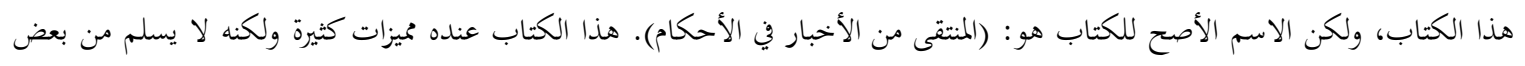

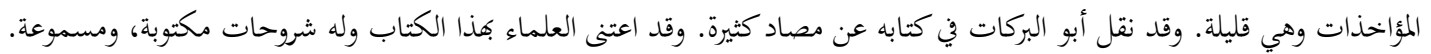

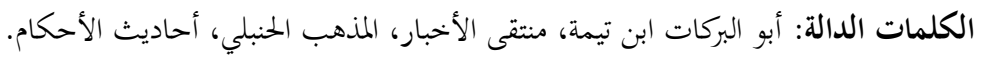




\title{
البصيرة: مبلة الصراهات الإهلامية \\ AL-BASHIRAH: JOURNAL OF ISLAMIC STUIDES \\ Vol. 1 No. 1(2020): 160-179
}

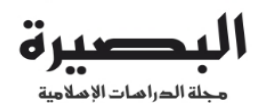

مجلة الصراهات الإصلامية

AL-BASHIRAH

Website: https://journal.stiba.ac.id

\section{Biography of al-Imām Majdu al-Dīn Abū al-Barakāt 'Abdu al-Salām Ibn Taimiyyah al-Harrān̄̄ and His Book Muntaqā al-Akhbār}

\author{
A ḥmad bin Muḥammad bin 'Abdul Hādī \\ Universitas Islam Madinah, Arab Saudi \\ Email: 381001867@iu.edu.sa \\ Muhammad Yusram \\ Sekolah Tinggi Ilmu Islam dan Bahasa Arab (STIBA) Makassar, Indonesia \\ Email: yusrananshar@stiba.ac.id
}

\begin{abstract}
This study aims to introduce one of the leading scholars in figh and hadith, Majdu al-Din Abu al-Barakat Abdu al-Salam Ibn Taymiyyah al-Harrani al-Hanbali and introduce his book al-Muntaqa. Among the objectives of this research are to remind the ummah and the students about the greatness of his position which may not be known by many people as well as to read the biographies of the role model of the ummah by imitating and following in the footsteps of his life journey. It also explains one of the most important literature in the hadith al-ahkam, namely muntaqa al-akhbar. In this study, the researchers employed a descriptive approach. Among the most important results of this research are that Imam Majdu al-Din Ibn Taymiyyah was born in Harran in 590 AH and died there in 653 AH. Majdu al-Din Abu al-Barakat is an expert in many disciplines including fiqh, hadith, al-nahw, al-qira'at, and ushul al-fiqh. He studied with many scholars and had traveled to Baghdad several times to recite knowledge in front of the scholars. Abu Al-Barakat wrote many books among which his phenomenal books are al-Muntaqa min al-Ahkam. His reason for writing the book was a request of a judge, Bahauddin bin Shaddad, to Imam Majd al-din to write it in Aleppo. The scholars differed in determining the name of this book and the strongest opinion is al-muntaqa fi al-akhbar fi al-ahkam. This book has many prominences yet does not free from some criticism even though it is in a small number. Abu Al-Barakat has quoted many references in his book. The scholars have an interest in this book by explaining its contents in the form of writing and lectures.
\end{abstract}

Keywords: Abu Al-Barakat Ibn Taymiah, Hadith Al-Ahkam, muntaqa al-akhbar, al-mazhab al-hambali.

$$
\begin{aligned}
& \text { المقدمة: } \\
& \text { الحمد لله الذي جعل في كل زمان فترة من الرسل، بقايا من أهل العلم يدعون من ضل إلى المدى، ويصبرون } \\
& \text { منهم على الأذى، يكيون بكتاب الله الموتى، ويبصرون بنور الله أهل العمى، ينفون عن كتاب الله تحريف } \\
& \text { الغالين، وانتحال المبطلين، وتأويل الجاهلين'، وصلى الله على سيد الأولين والآخرين، وقائد الغر الميامين، } \\
& \text { محمد بن عبد الله، وعلى آله وصحبه أجمعين. } \\
& \text { ' مقتبسة من مقدمة الإمام أحمد بن حنبل رحمه الله ورضي عنه في كتابه (الرد على الجهمية والزنادقة)، بتحقيق: صبري بن سلامة شاهين، دار }
\end{aligned}
$$

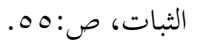

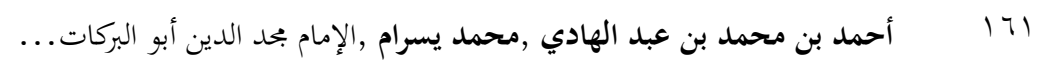




\section{البصيرة: مبلة الصراهات الإهلامية AL-BASHIRAH: JOURNAL OF ISLAMIC STUIDES \\ Vol. 1 No. 1(2020): 160-179}

Website: https://journal.stiba.ac.id

أما بعد: فهذا تعريف بأحد أئمة الإسلام وعلمائهم على وجه العموم، والحنابلة على وجه الخصوص، وهو الخها

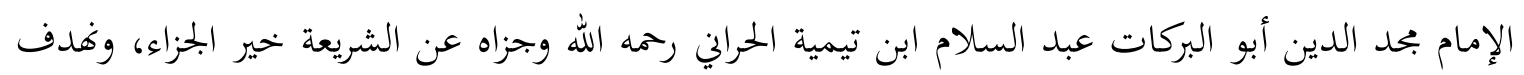

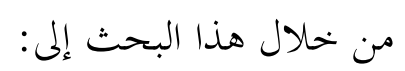
ا ب تزكير الأمة، وطلبة العلم بقدر هذا العالم الجليل الذي ربما لا يعرفه الكثيرون.

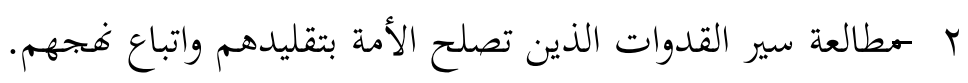

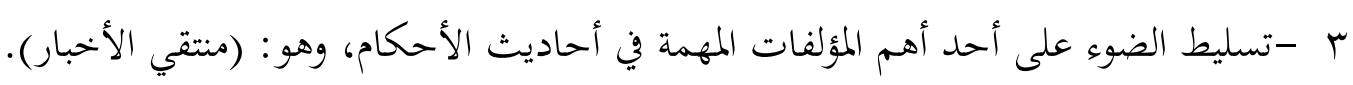
وقد قسم الباحثان هذا البحث إلى هذه المقدمة، ومبحثين، وخاتمة كالتالي:

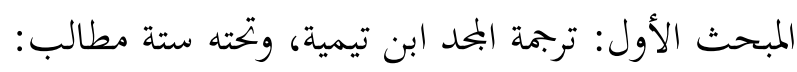

$$
\begin{aligned}
& \text { • المطلب الأول: اسمه وولادته ونسبه ونشأته. } \\
& \text { • المطلب الثاني: شيوخه وتلاميذه. } \\
& \text { • المطلب الثالث: طلبه للعلم ورحلاته. } \\
& \text { • المطلب الرابع: عقيدته ومذهبه. }
\end{aligned}
$$

• • المطلب الخامس: مكانته وثناء العلماء عليه.

$$
\text { • المطلب السادس: مؤلفاته ووفاته. }
$$

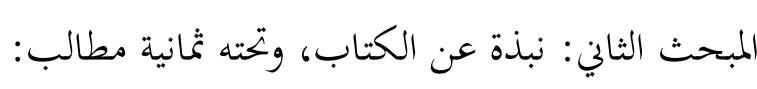

$$
\begin{aligned}
& \text { • المطلب الأول: أهمية الكتاب. } \\
& \text { • المطلب الثاني: سبب تأليف الكتاب. } \\
& \text { • المطلب الثالث: تحقيق اسم الكتاب. } \\
& \text { • المطلب الرابع: طبعات الكتاب. } \\
& \text { • المطلب الخامس: مميزات الكتاب. } \\
& \text { • المطلب السادس: المؤاخذات على الكتاب. }
\end{aligned}
$$

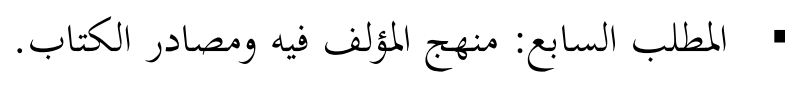

$$
\begin{aligned}
& \text { • - ل المطلب الثامن: شروحاته. }
\end{aligned}
$$

وقد اتبع الباحثان في هذا البحث المنهج الوصفي، وذلك بتتبع وجمع المعلومات المتعلقة 


\section{البصيرة: مبلة الصراهات الإهلامية AL-BASHIRAH: JOURNAL OF ISLAMIC STUIDES \\ Vol. 1 No. 1(2020): 160-179}

Website: https://journal.stiba.ac.id

بوصف وترجمة الإمام البحد ابن تيمية، والمتعلقة بوصف كتابه (منتقى الأخبار)، و ونسأل الله سبحانه وتعالى أن يتقبله منا إنه سميع عليم.

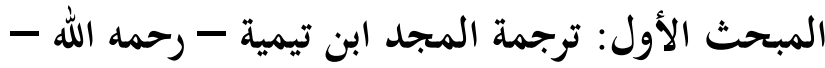

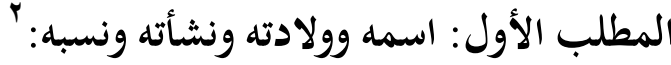

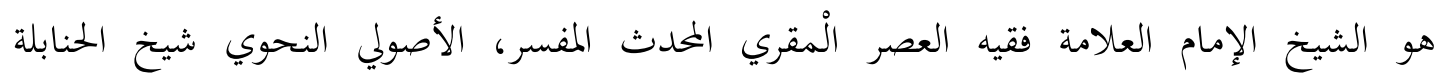
بجد الدين أبو البركات عبد السلام بن عبد الله بن الخضر بن محمد بن علي الحراني، ابن تيمية.

$$
\begin{aligned}
& \text { ولد في حران" سنة تسعين وخمس مائة } \\
& \text { المطلب الثاني: شيوخه وتلاميذه } \\
& \text { أولاً: شيوخه: } \\
& \text { أخذ عن كثير من العلماء والمشايخ من أشهرهم: } \\
& \text { 1- عمه فخر الدين الخطيبْ }
\end{aligned}
$$

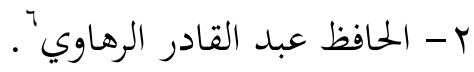

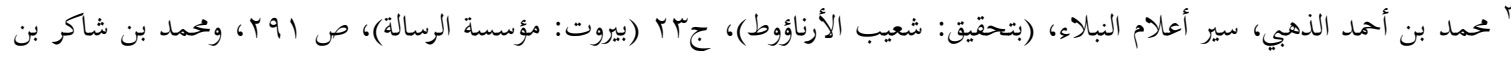

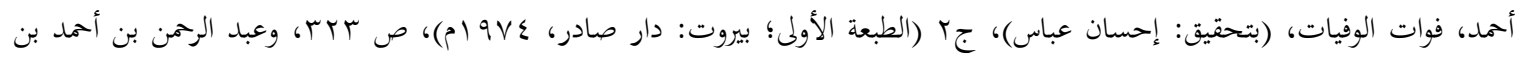

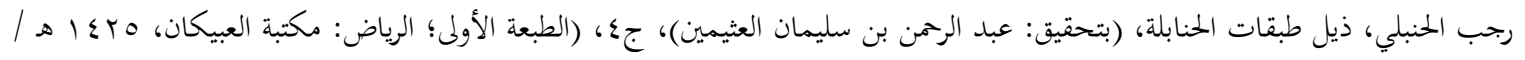

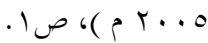

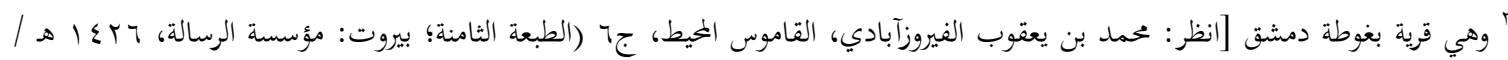

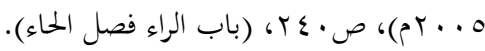

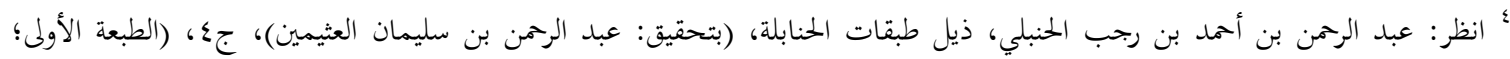

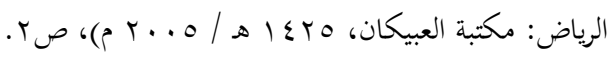

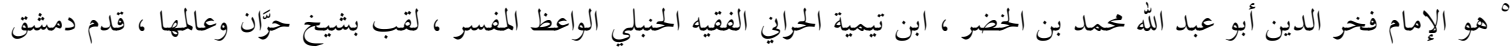

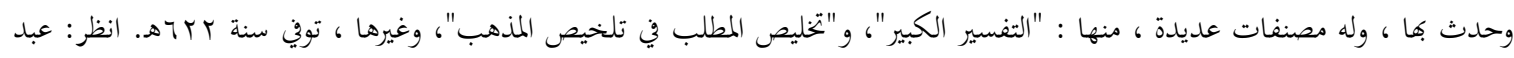

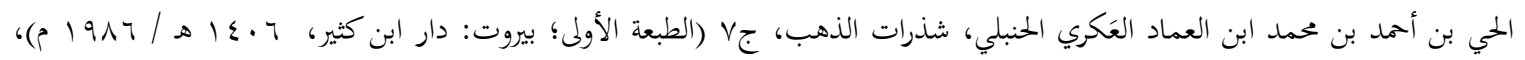

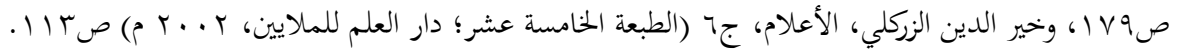

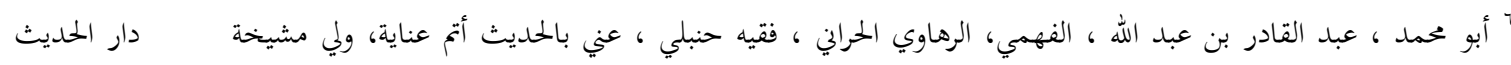

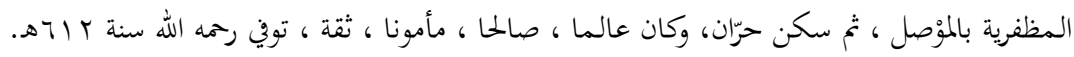

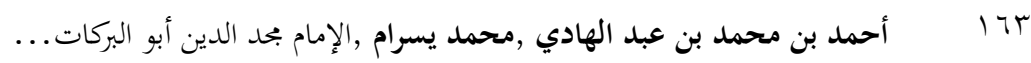




\section{البصيرة: مبلة الصراهات الإهلامية AL-BASHIRAH: JOURNAL OF ISLAMIC STUIDES \\ Vol. 1 No. 1(2020): 160-179}

Website: https://journal.stiba.ac.id

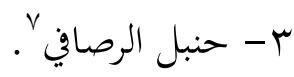

$$
\begin{aligned}
& \text { ع - أبو أحمد بن سكينة. } \\
& \text { ثانياً: تلاميذه } \\
& \text { وقد أخذ عنه العديد من طلاب العلم لعل من أشهرهم: }
\end{aligned}
$$

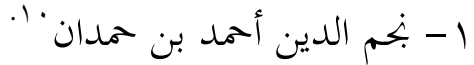

$$
\begin{aligned}
& \text { r- أبو إسحاق بن الظاهري الحافظ' ' . } \\
& \text { r- أبو محمد ، عبد الرحمن بن سليمان بن عبد العزيز الحربي با. }
\end{aligned}
$$

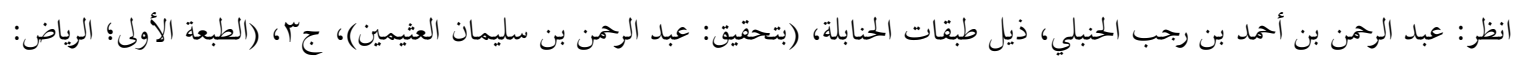

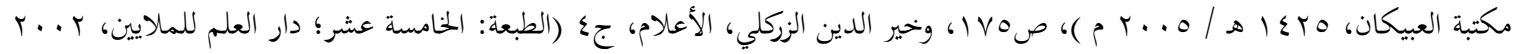

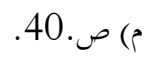

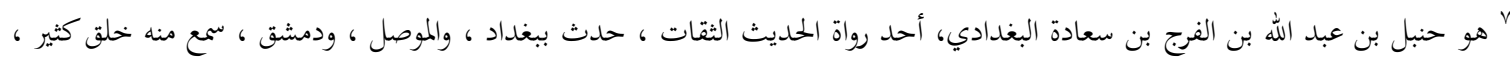

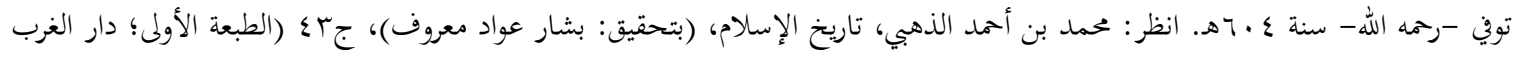

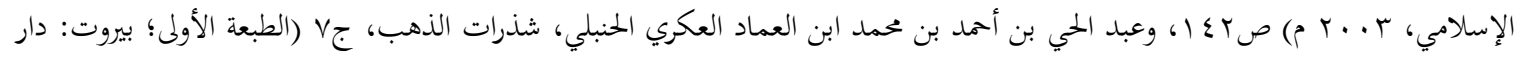

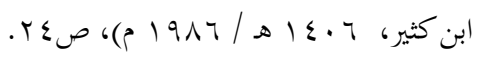

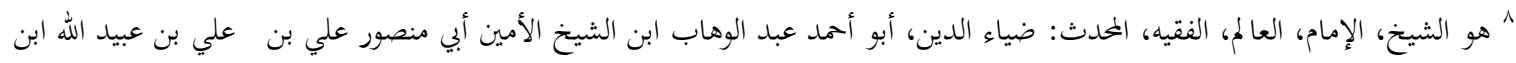

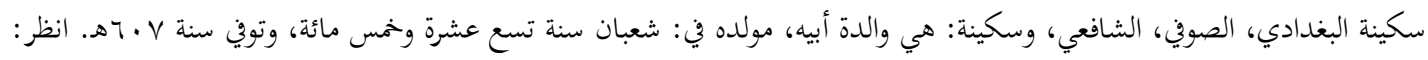

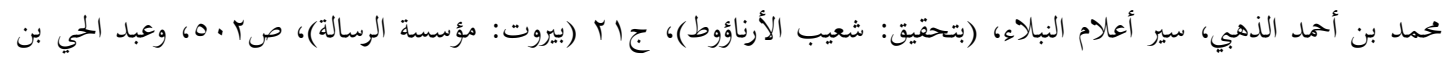

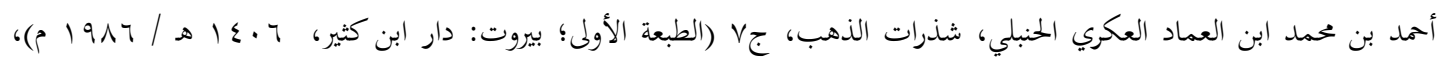

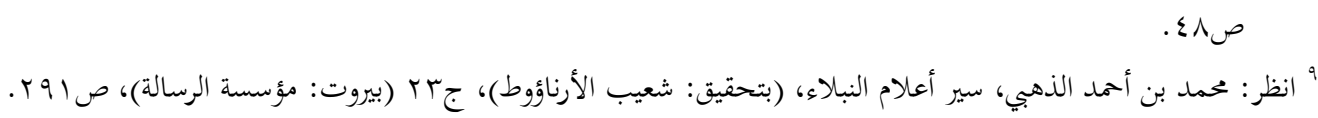

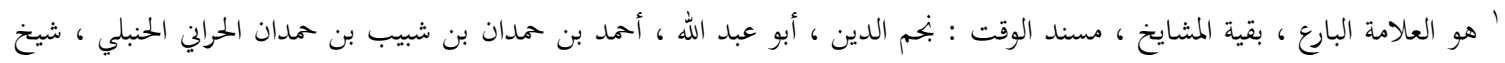

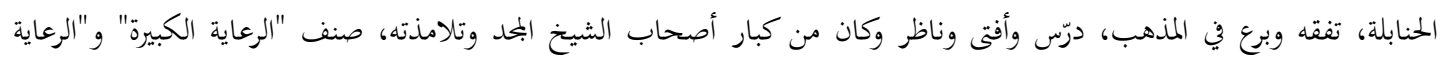

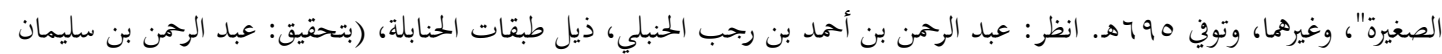

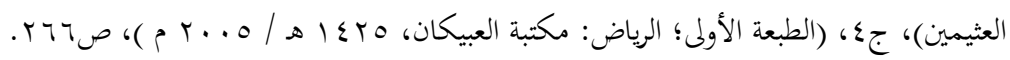

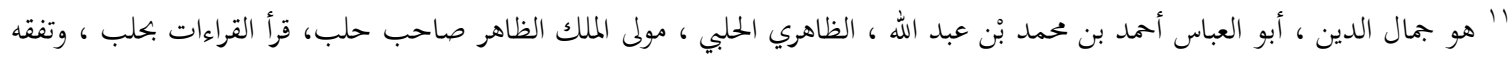

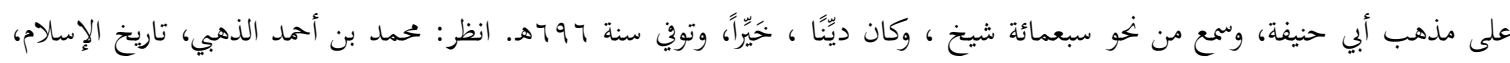

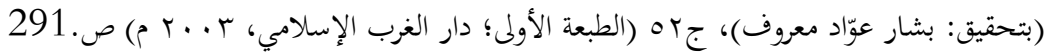

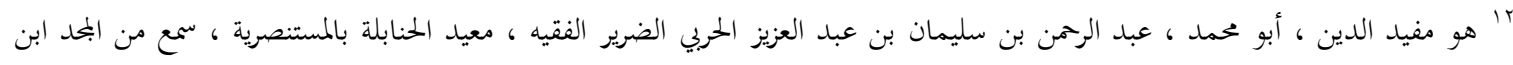

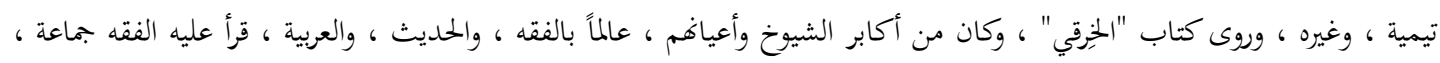




\section{البصيرة: مبلة الصراهات الإهلامية AL-BASHIRAH: JOURNAL OF ISLAMIC STUIDES \\ Vol. 1 No. 1(2020): 160-179}

Website: https://journal.stiba.ac.id

$$
\begin{aligned}
& \text { ع - عبد المؤمن بن خلف التوني الشافعي" '. } \\
& \text { المطلب الثالث: طلبه للعلم ورحلاتهء }
\end{aligned}
$$

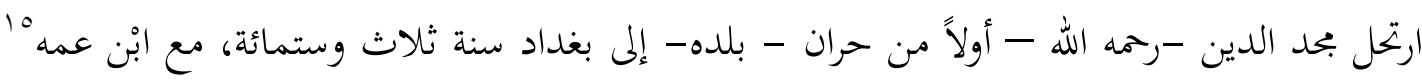

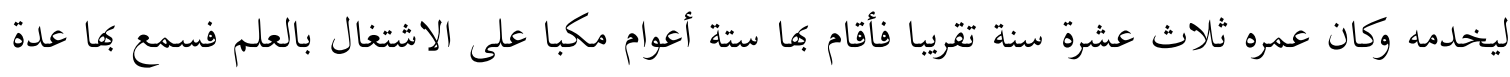
مشايخ منهم:

$$
\text { عبد الوهاب ابن سكينة، ثم رجع إلى حران واشتغل بها على عمه الخطيب فخر الدين. }
$$

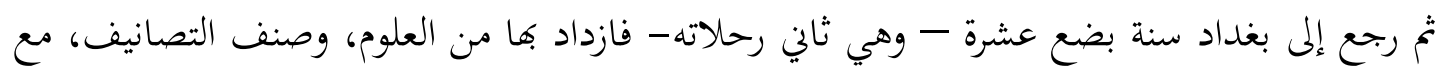

$$
\text { الدين والتقوى، وحسن الاتباع، وجلالة العلم. }
$$

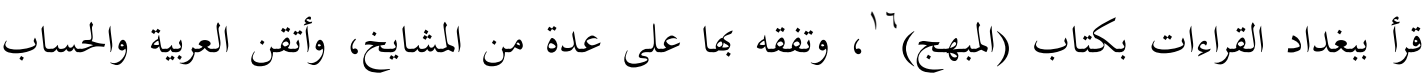

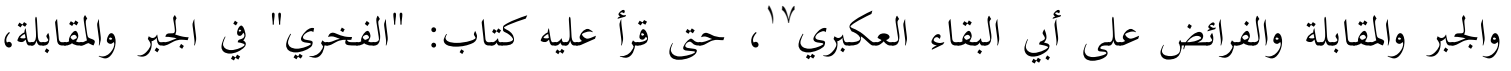

$$
\text { وبرع في هذه العلوم وغيرها. }
$$

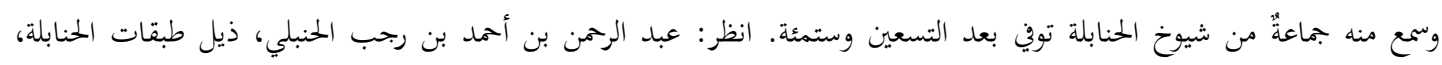

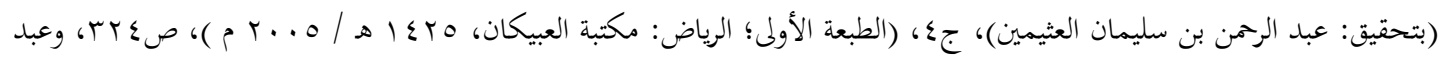

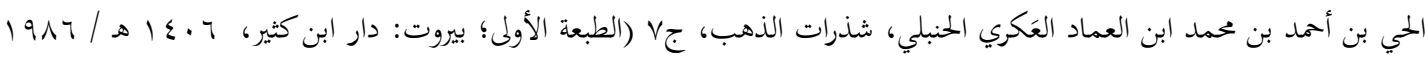

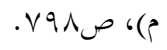

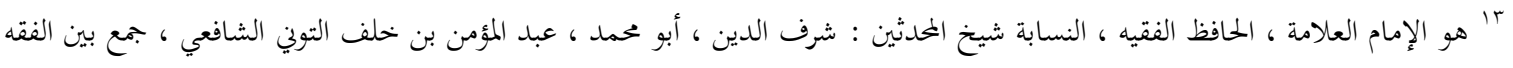

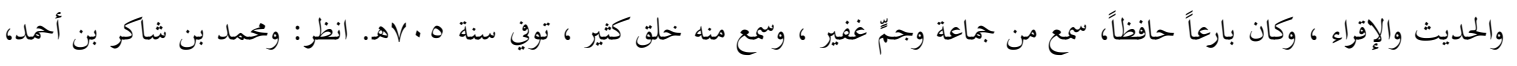

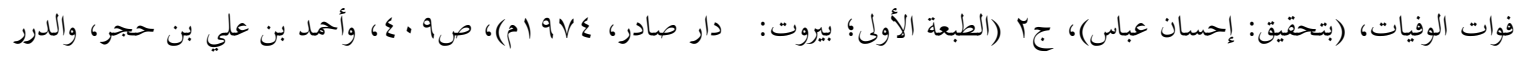

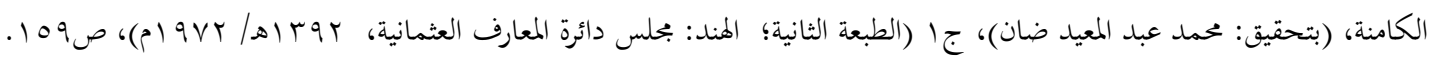

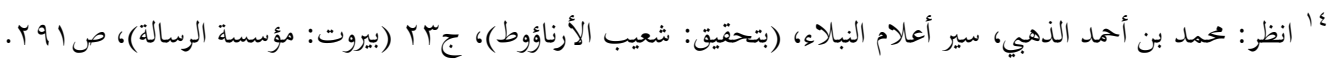
10 أهو: سيف الدين عبد الغني. 17' ومؤلفه هو: سبط الخياط علي بن عبد الواحد بن سلطان.

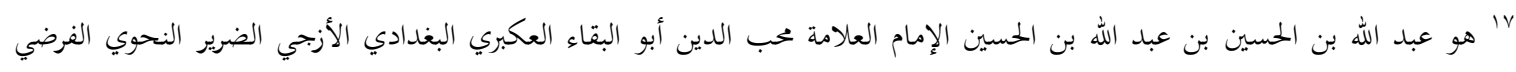

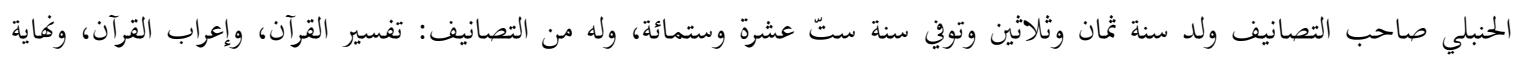

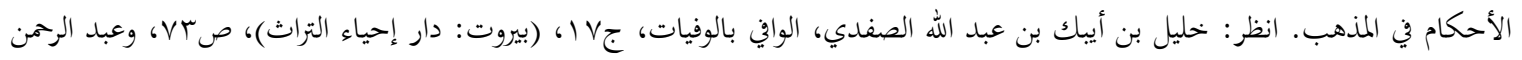

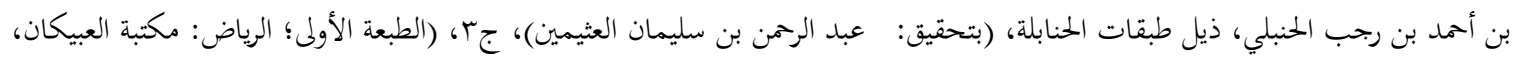

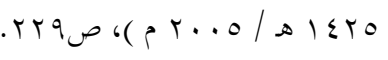
170 


\section{البصسيرة: مبلة الصراهات الإهلاهية AL-BASHIRAH: JOURNAL OF ISLAMIC STUIDES \\ Vol. 1 No. 1(2020): 160-179}

Website: https://journal.stiba.ac.id

وقد حج في سنة إحدى وخمسين - وهي ثالث رحلاته- على درب العراق، وانبهر علماء بغداد

لذكائه وفضائله، والتمسوا منه الإقامة عندهم، فتقلى وحسن بالأهل والوطن.

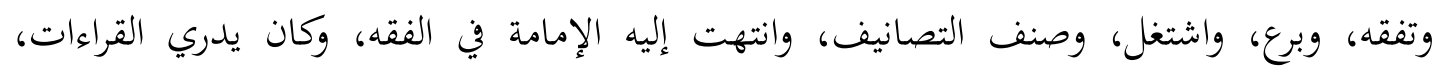

$$
\text { وصنف فيها أرجوزة. }
$$

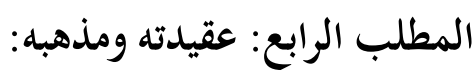

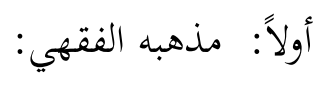

أما فيما يتعلق بمذهب الإمام المحد ابن تيمية الفقهي فهو حنبلي المذهب بلا خحلاف، ويظهر هذا من

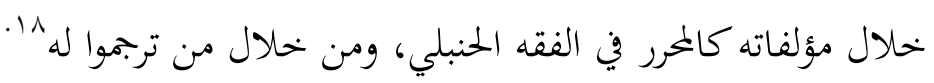
ثانياً: عقيدته:

وأما بالنسبة لعقيدته فلا يمكن الاطلاع بشكل دقيق على عقيدة المحد ابن تيمية - رمهه الله - وذلك ألك

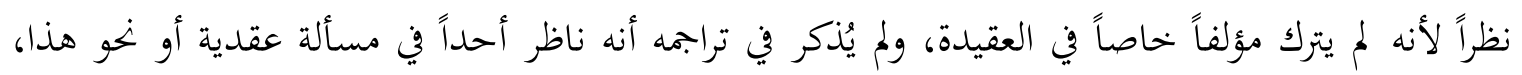

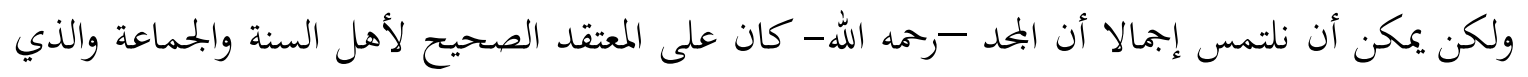

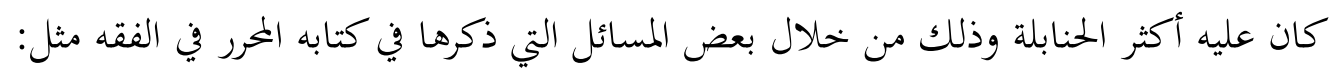

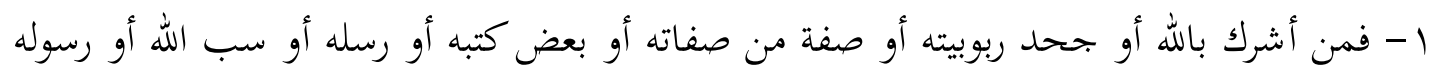
فقد كفر.

r- من جحد وجوب عبادة من الخمس أو تحريم الزنا أو الخمر أو حل اللحم والخبز ونخوه من كن

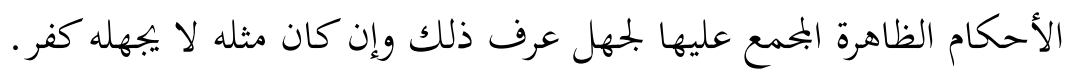

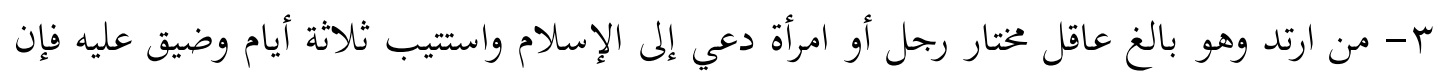

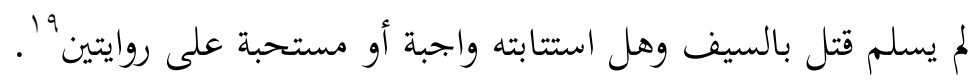
ع - لا تقبل شهادة من فسقه لبدعة كمن يعتقد مذهب الرافضة أو الجهمية أو المعتزلة تقليدا ويتخرج

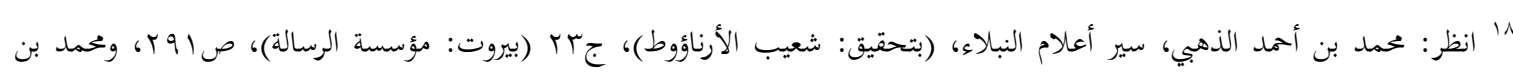

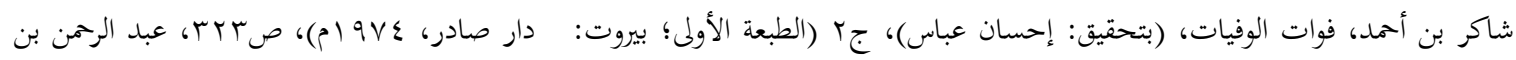

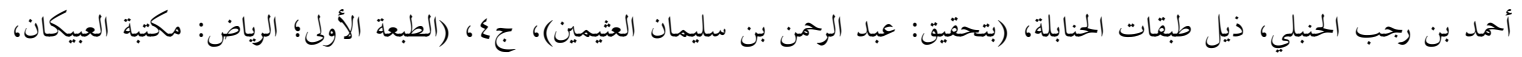

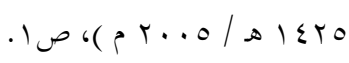

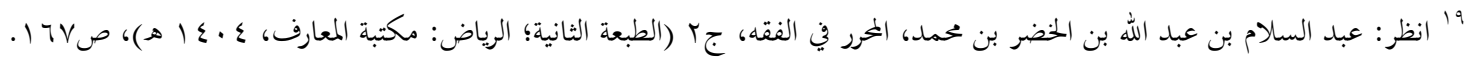

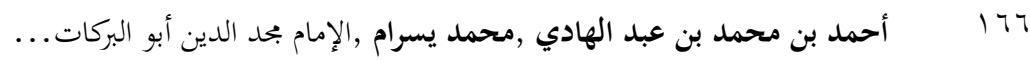




\section{البصيرة: مبلة الصراهات الإهلامية AL-BASHIRAH: JOURNAL OF ISLAMIC STUIDES \\ Vol. 1 No. 1(2020): 160-179}

Website: https://journal.stiba.ac.id

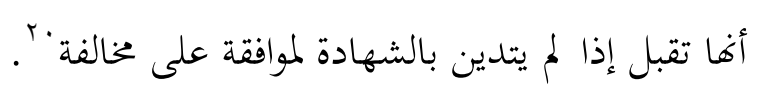

- فيلاحظ من هذه النصوص بعض القواعد العامة لعقيدة أهل السنة والجماعة مثل:

$$
\begin{aligned}
& \text { ا - تعظيم الله سبحانه، وإثبات كفر من سبه أو سب رسوله. } \\
& \text { r- الإيمان بصفات الله، وكفر من أنكر شيئاً منها. } \\
& \text { r- إثبات أن الذنوب تئثر في الإيمان بل قد تحبطه من أصله. }
\end{aligned}
$$

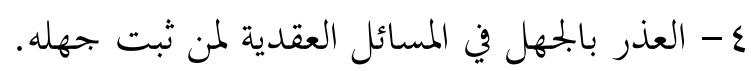

ه- تبديع المخالفين لأصول اعتقاد أهل السنة كالرافضة والجهمية والمعتزلة.

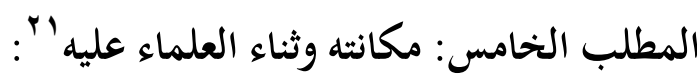

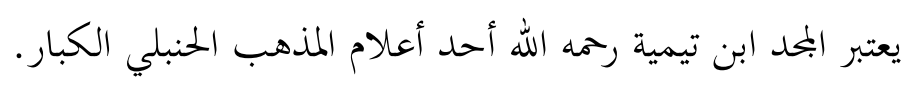

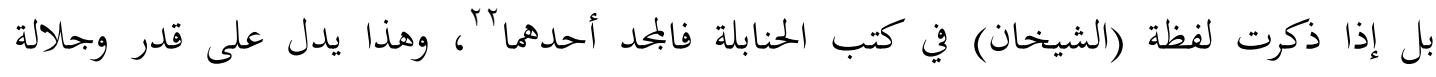

$$
\text { هذا الإمام - رحمه الله- عند الحنابلة. }
$$

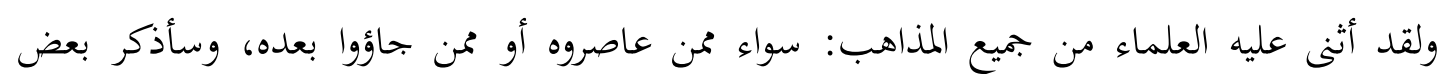

$$
\text { العبارات التي ذكرت في ترجمته في مدحه والثناء عليه: }
$$

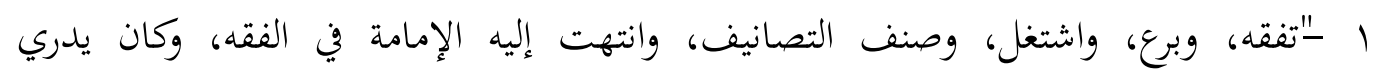

$$
\text { القراءات، وصنف فيها أرجوزة". }
$$

r r ب - وكان فرد زمانه في معرفة المذهب، مفرط الذكاء، متين الديانة، كبير الشأن".

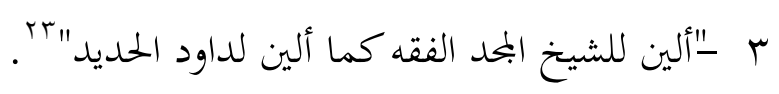

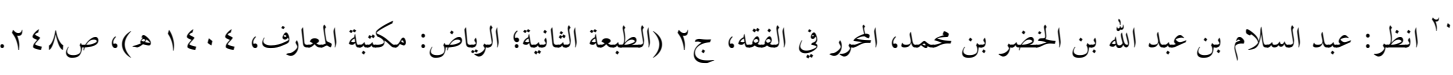

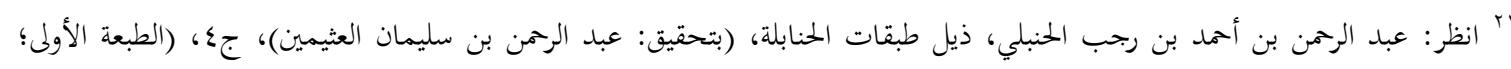

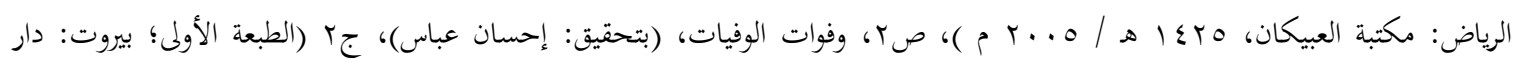

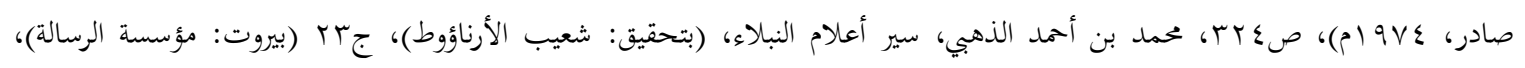

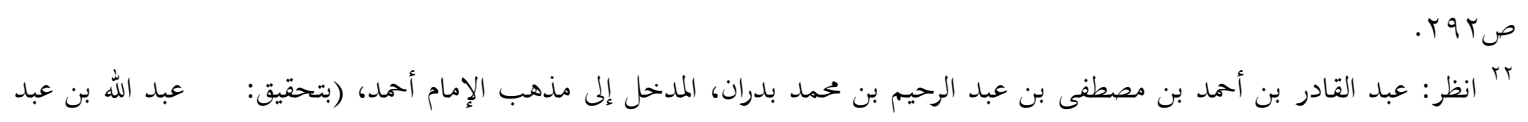

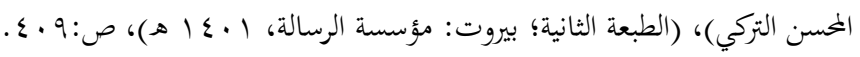

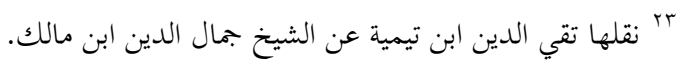

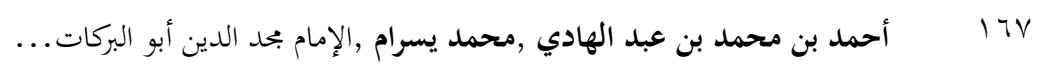




\section{البصسيرة: مبلة الصراهات الإهلاهية AL-BASHIRAH: JOURNAL OF ISLAMIC STUIDES \\ Vol. 1 No. 1(2020): 160-179}

Website: https://journal.stiba.ac.id

ع ققال بعض طلابه \& : كنت أطالع على درس الشيخ وما أبقي مككنا، فإذا أصبحت وحضرت

$$
\text { ينقل أشياء كثيرة لم أعرفها قبل". }
$$

ه قال حفيده ": كان جدنا عجبا في سرد المتون، وحفظ مذاهب الناس، وإيرادها بلا كلفة".

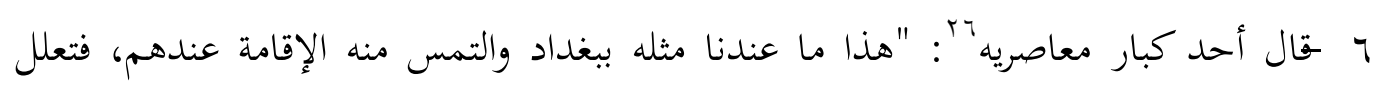

$$
\text { بالأهل والوطن". }
$$

V قال حفيده YrV " "كان الجحد إذا دخل الخلاء يقول لي: اقرأ في هذا الكتاب، وارفع صوتك حتى

$$
\text { أسمع". }
$$

ᄉ - -وكان إماماً حجة بارعاً في الفقه والحديث، وله يد طولى في التفسير ومعرفة تامة في الأصول

$$
\begin{aligned}
& \text { والاطلاع على مذاهب الناس، وله ذكاء مفرط، ولم يكن في زمانه مثله". }
\end{aligned}
$$

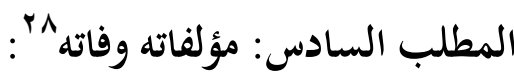

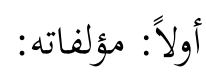

$$
\begin{aligned}
& \text { كان للمجد ابن تيمية رحمه الله العديد من المؤلفات النافعة من أهمها: } \\
& \text { 1- أطراف أحاديث التفسير. }
\end{aligned}
$$

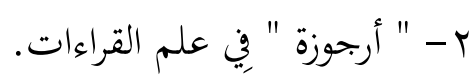

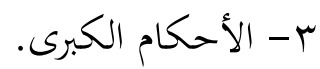

$$
\begin{aligned}
& \text { ع - المنتقي من أحاديث الأَحْكام. (وهو مطبوع) }
\end{aligned}
$$

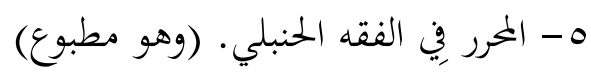

$$
\begin{aligned}
& \text { ع بوهو العلامة ابن حمدان. }
\end{aligned}
$$

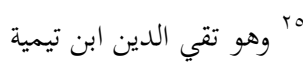

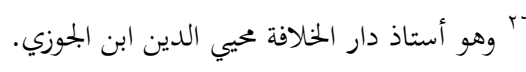

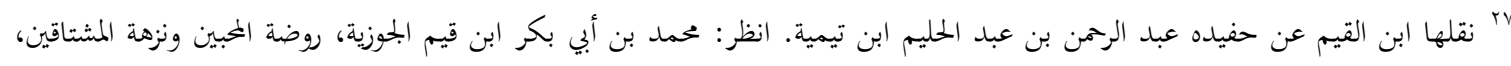

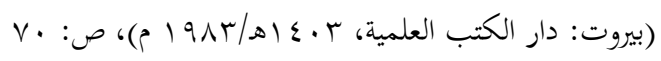

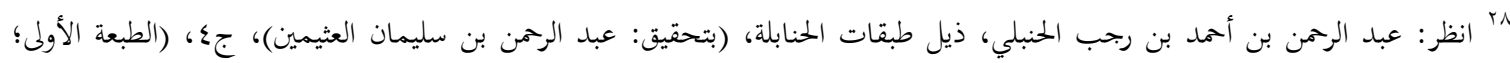

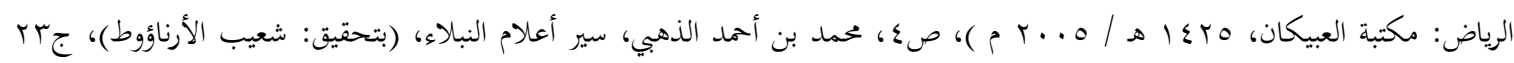

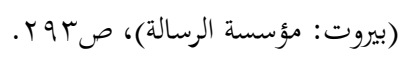




\section{البصيرة: مبلة الصراهات الإهلامية AL-BASHIRAH: JOURNAL OF ISLAMIC STUIDES \\ Vol. 1 No. 1(2020): 160-179}

Website: https://journal.stiba.ac.id

$$
\begin{aligned}
& \text { צ- منتهى الغاية فِي شرح الهداية. (وهو مطبوع) }
\end{aligned}
$$

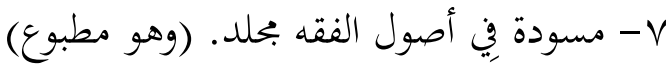

$$
\begin{aligned}
& \text { ثانياً: وفاته: }
\end{aligned}
$$

توفي يوم عيد الفطر بعد صلاة الجمعة من سنة اثنتين وخمسين وستمائة بحران، ودفن باهرها.

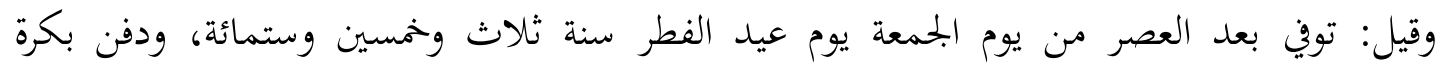

$$
\text { وصلى عليه أبو الفرج عبد القاهر بن أبي محمد عبد الغني بن أبي عبد اللَّه ابن تيمية. }
$$

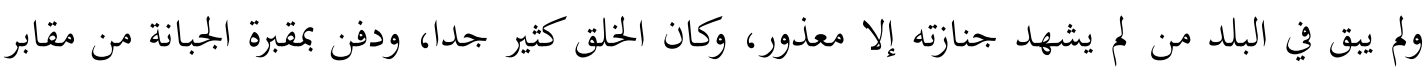

رحمه الله رممة واسعة، ونفعنا بعلمه.

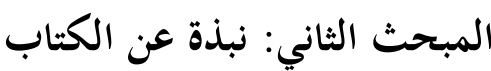

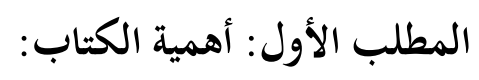

يُعد كتاب منتقى الأخبار من أهم كتب أحاديث الأحكام وأجمعها وأشهرها كما وصفه جمع من

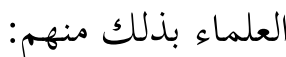

1- الحافظ ابن رجب به حيث قال: " المنتقي من أحاديث الأحكام " وهو الكتاب المشهور، انتقاه

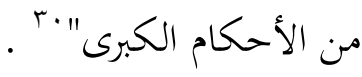

r- الإمام ابن الملقن بr حيث قال: "وأحكام الحافظ بحد الدين عبد السلام ابن تيمية، الْمسمى

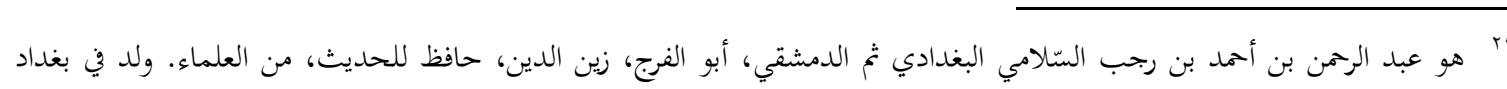

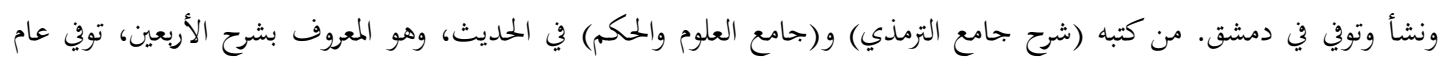
لry

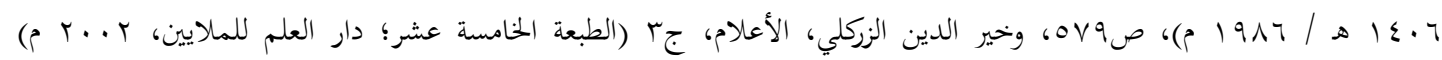
عبد الرمن بن أمد بن رجب الحنبلي، ذيل طبقات الحنابلة، (بتحقيق: عبد الرمن بن سليمان العثيمين)، ج؛، (الطعة الأولى؛ الرياض:

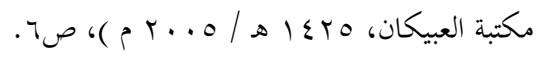

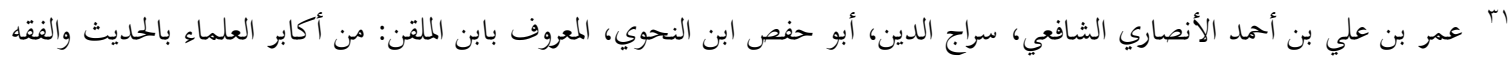

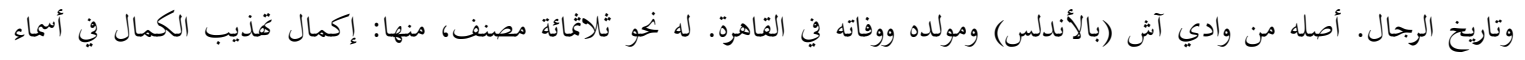
أ 179 


\section{البصسيرة: مبلة الدراهات الإهلامية AL-BASHIRAH: JOURNAL OF ISLAMIC STUIDES \\ Vol. 1 No. 1(2020): 160-179}

Website: https://journal.stiba.ac.id

بدالمنتقى)، وهو كاسمه، وما أحسنه، لولا إطلاقه فِ كثير من الأحاديث الْعزو إلى (كتب) الأئمة دون

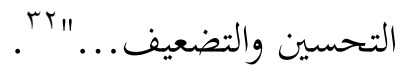

r- الإمام الشوكاني حيث قال: " "لم ينسج على بديع منواله ولا حرر على شكله ومثاله أحد من

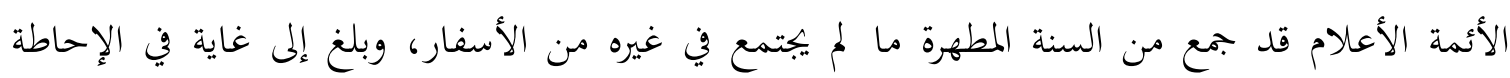

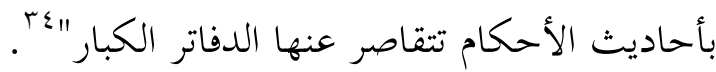

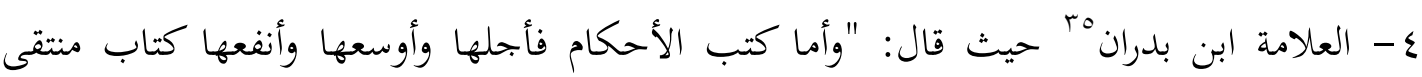

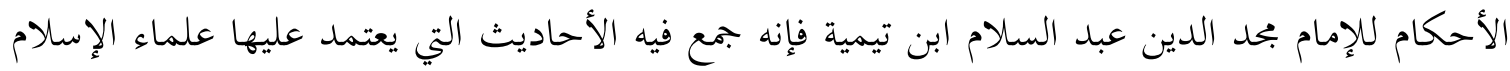

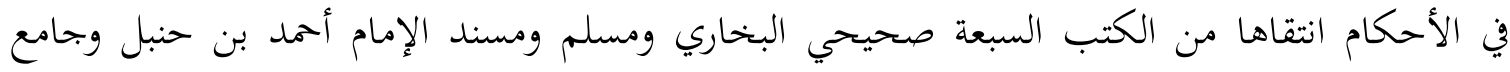

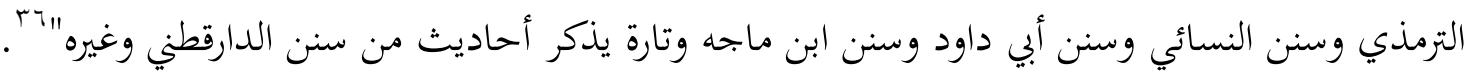

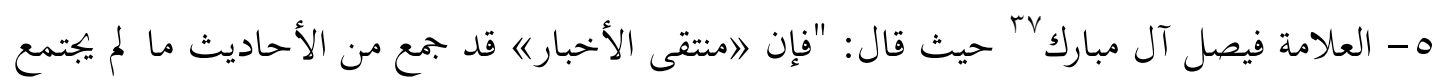

الرجال، وخلاصة البدر المنير في تخريج أحاديث شرح الوجيز للرافعي، توفي سنوة ع ـ 1هـ بالقاهرة. انظر: خير الدين الزركلي، الأعلام، جه

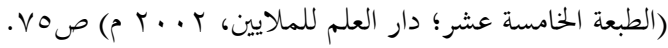

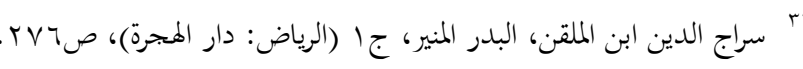

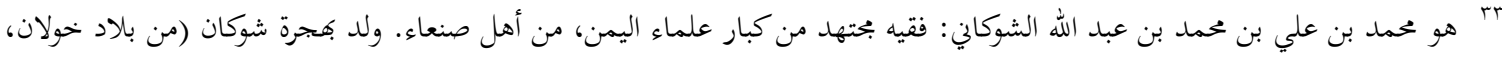

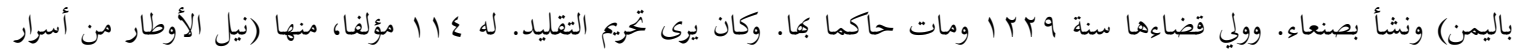

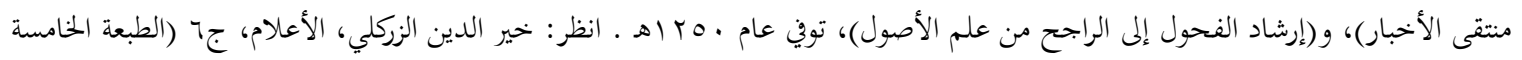

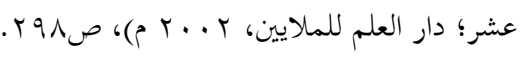

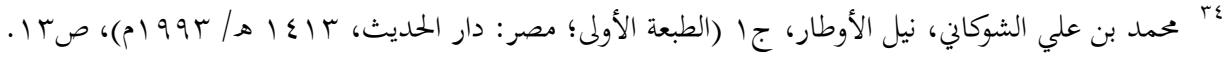

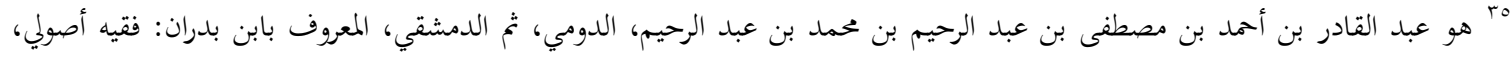

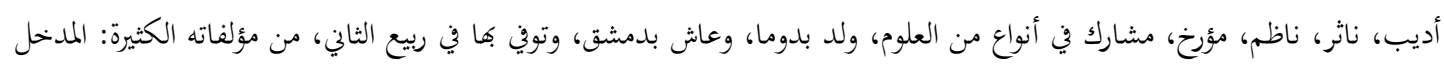

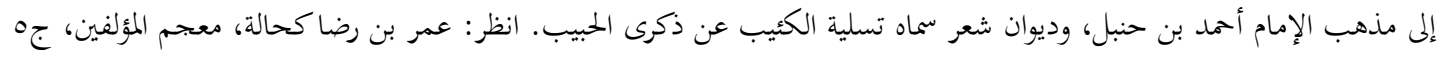

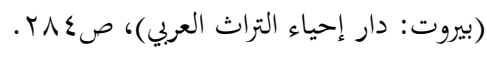

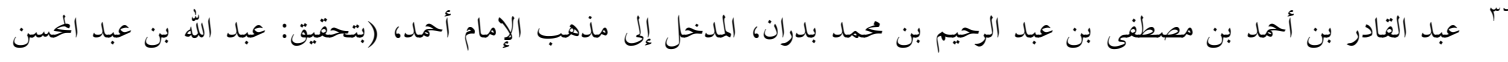

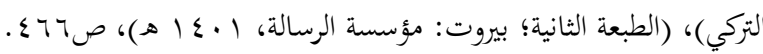

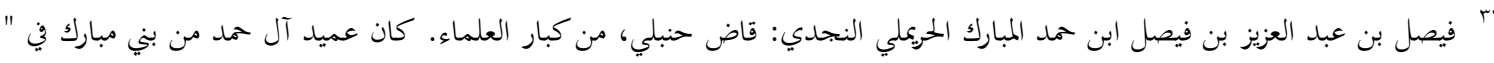

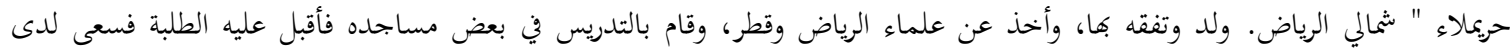

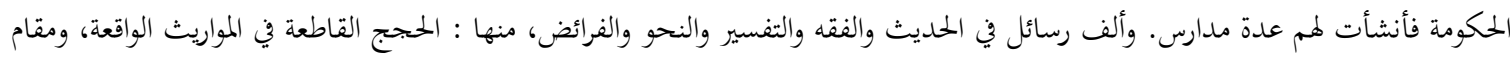

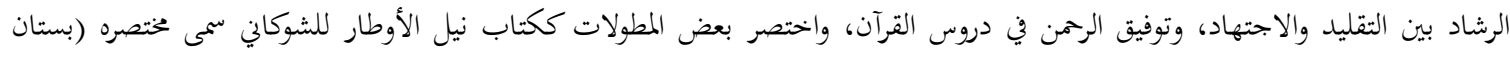

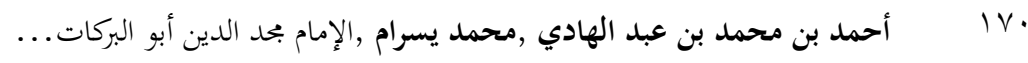




\section{البصيرة: مبلة الصراهات الإهلامية AL-BASHIRAH: JOURNAL OF ISLAMIC STUIDES \\ Vol. 1 No. 1(2020): 160-179}

Website: https://journal.stiba.ac.id

في غيره من كتب الأحكام، وصار مرجعًا للعلماء عند الحاجة إلى طلب الدليل لاسيما وهو تأليف علامة

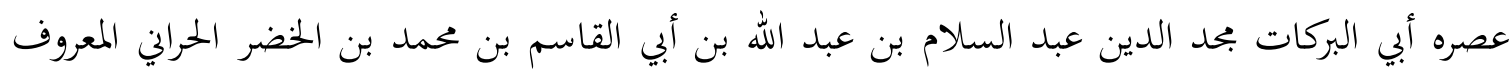

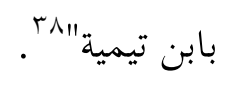

المطلب الثاني: سبب تأليف الكتاب:

لم ينص الإمام بحد الدين ابن تيمية على سبب تأليفه لكتابه (المنتقى) في مقدمته كما هي عادة كثير

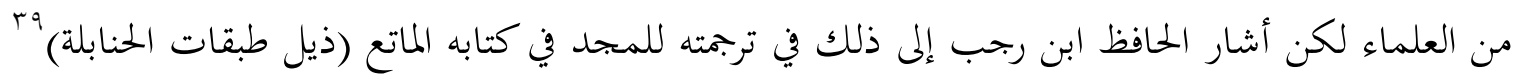

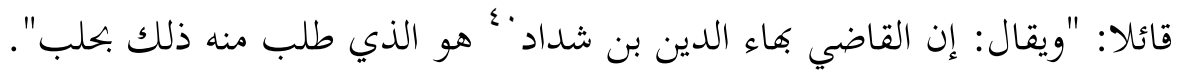

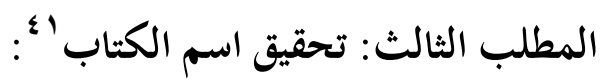
المطالع لمخطوطات ومطبوعات الكتاب يجد اختلافا يسيرا في ضبط اسمه، ويمكن استعراض أشهر هذه

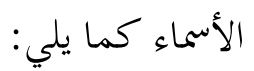
ا بالمنتقى المسمى الأحكام. r بلمنتقى في الأحكام الشرعية من كلام خير البرية، وهذه التسمية اختارها محقق الكتاب الشيخ طارق بن عوض الله. r بلمنتقى من الأخبار في الأحكام، وهذه التسمية اختارها الإمام الشوكاني في مقدمة شرحه

الأحبار) وأضاف إليه زيادات، توفي سنة بrVاهـ انظر: خير الدين الزركلي، الأعلام، جه (الطبعة الخامسة عشر؛ دار العلم للملايين، (

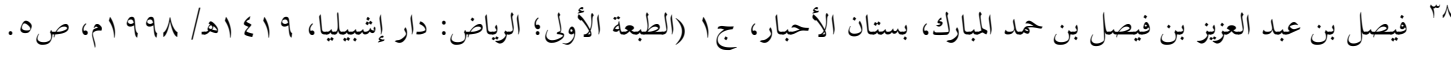

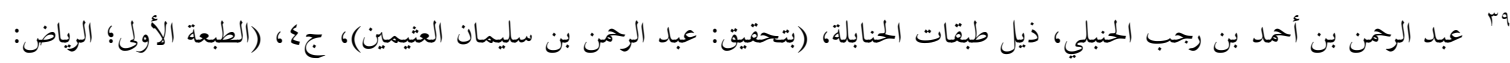

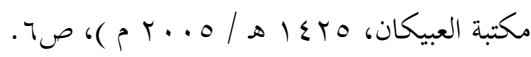

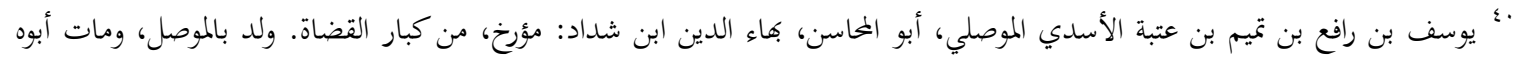

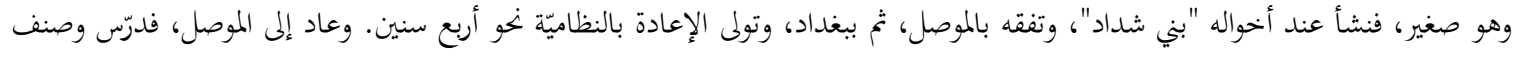

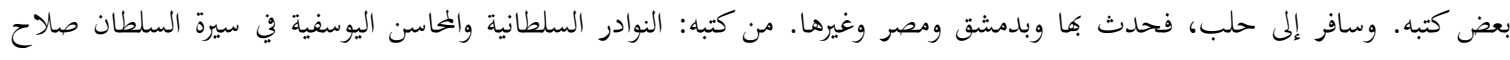

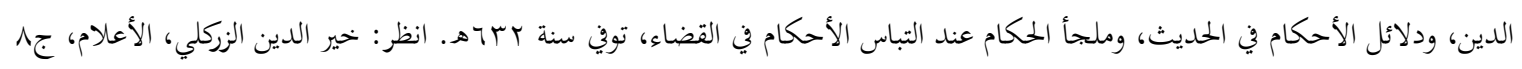

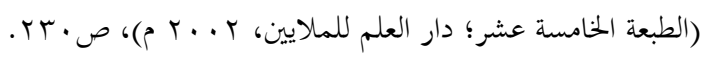

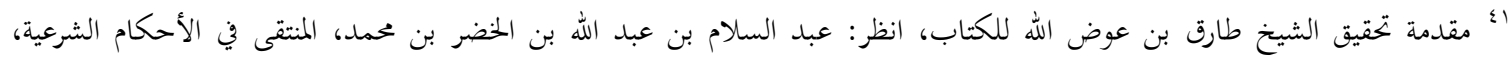

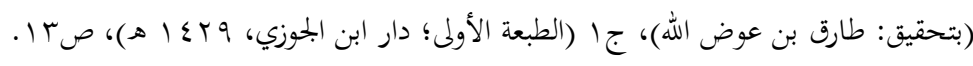
... IVI 


\section{البصيرة: مبلة الصراهات الإهلامية AL-BASHIRAH: JOURNAL OF ISLAMIC STUIDES \\ Vol. 1 No. 1(2020): 160-179}

Website: https://journal.stiba.ac.id

$$
\text { ع المنتقى من أخبار المصطفى. }
$$

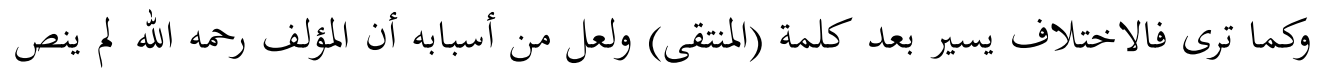

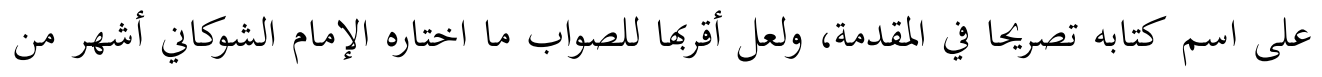

$$
\text { المطلب الرابع: طبعات الكتاب بـ الكتاب وهي: (المنتقى من الأخبار في الأحكام)، والله أعلم. }
$$

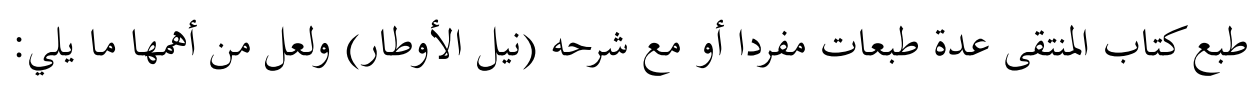

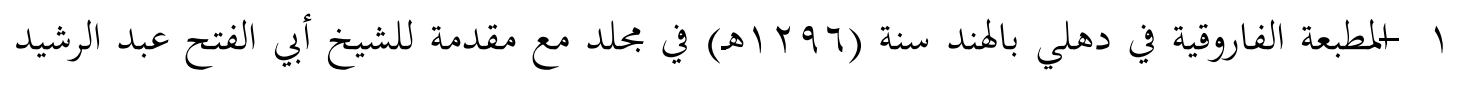

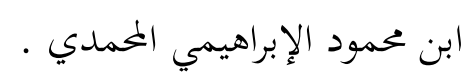

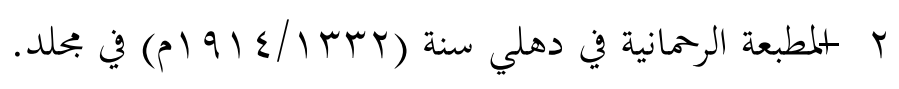

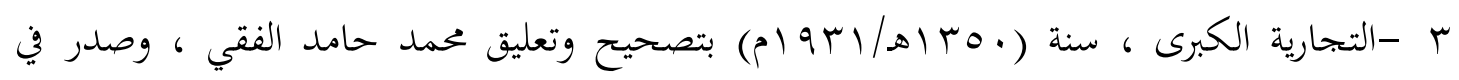

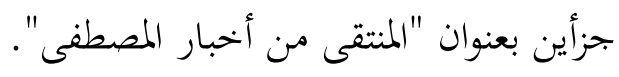

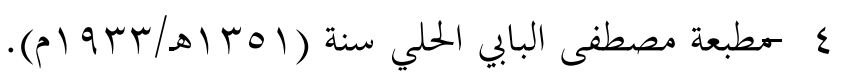

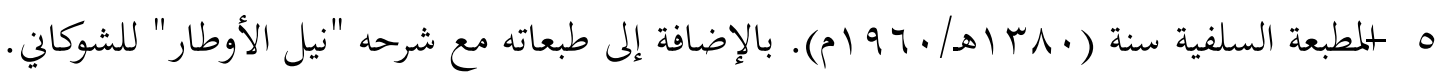

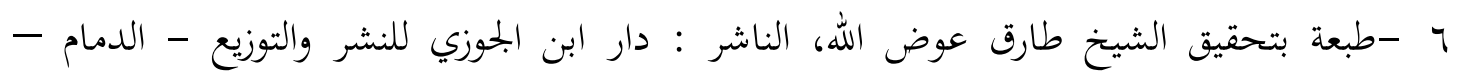

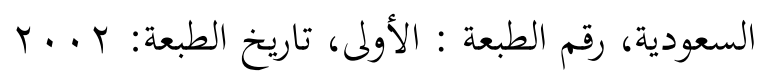

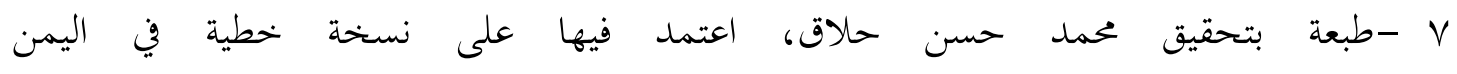

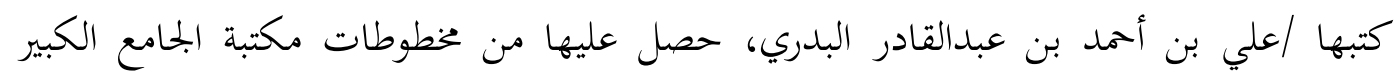

$$
\text { صنعاء. }
$$

$$
\text { المطلب الخامس: مميزات الكتاب: }
$$

$$
\text { يتميز كتاب منتقى الأخبار بعدة مميزات من أهمها: }
$$

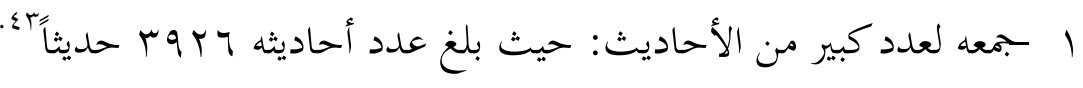

rs http://www.ahlalhdeeth.com/vb/showthread.php?t=76025\&highlight=\%CD\%E1\%C7\%DE

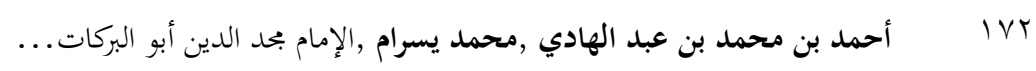




\section{البحيرة: مبلة الصراهات الإهلامية AL-BASHIRAH: JOURNAL OF ISLAMIC STUIDES \\ Vol. 1 No. 1(2020): 160-179}

Website: https://journal.stiba.ac.id

r ترتيب أحاديثه على أبواب كتب الفقه: حيث بدأ بكتاب الطهارة وانتهى بكتاب الأقضية

$$
\text { والأحكام. }
$$

r rترتيب أبوابه ببعض ما دلت عليه أحاديثه من الفوائد: مثل قوله: (باب: أن ما لا نفس له

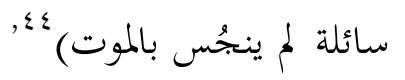

ع +لاختصار بالعزو إلى المسانيد وعدم ذكر الأسانيد.

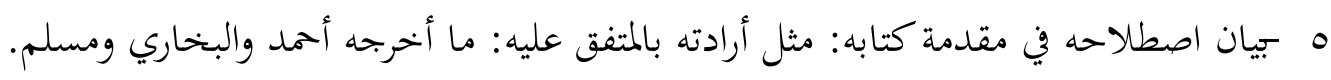

$$
\text { T - خكر بعض آثار الصحابة. }
$$

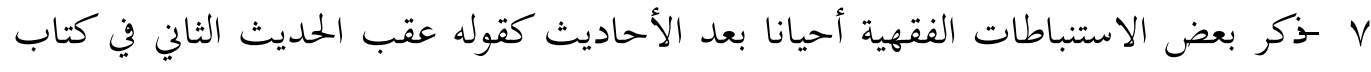

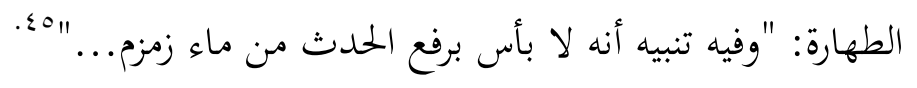

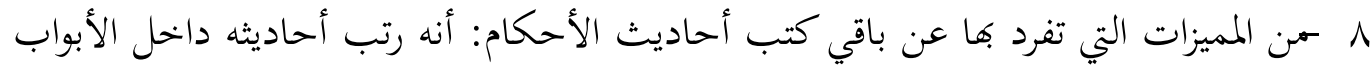

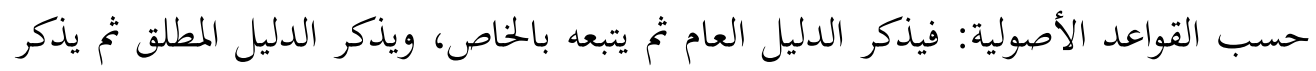

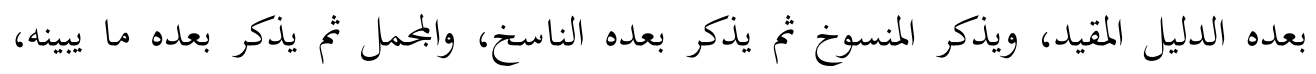

$$
\text { وهكذآ }
$$

المطلب السادس: المؤاخذات على الكتاب v؛

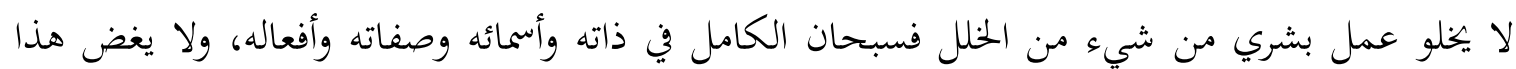

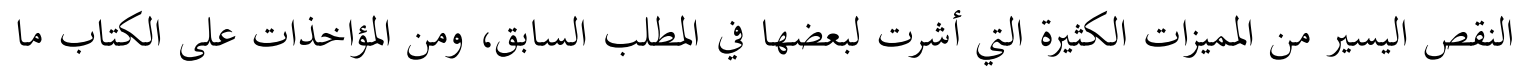

rاء انظر: عبد السلام بن عبد الله بن الخضر بن محمد، المنتقى في الأحكام الشرعية، (بتحقيق: طارق بن عوض الله)، جا (الطبعة الأولى؛ دار

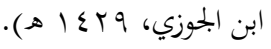
؛؛ انظر: عبد السلام بن عبد الله بن الخضر بن محمد، المنتقى في الأحكام الشرعية، (بتحقيق: طارق بن عوض الله)، جا (الطبعة الأولى؛ دار

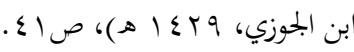
ه؛ انظر: عبد السلام بن عبد الله بن الخضر بن محمد، المنتقى في الأحكام الشرعية، (بتحقيق: طارق بن عوض الله)، جا (الطبعة الأولى؛ دار

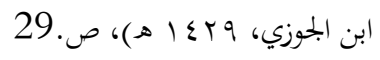

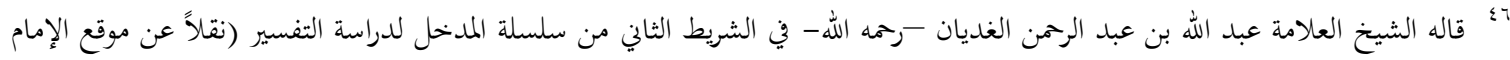

$$
\text { الآجري على الشبكة العنكبوتية). }
$$

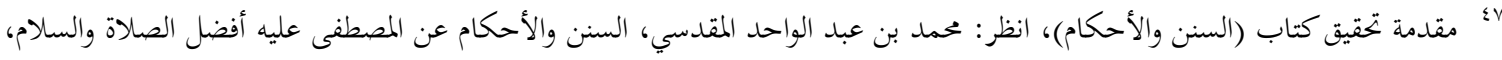

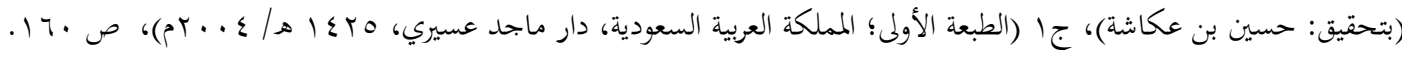

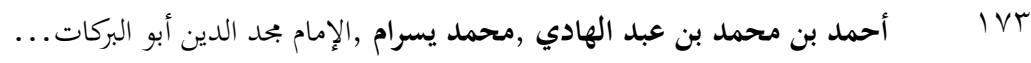




\section{البصيرة: مبلة الصراهات الإهلامية AL-BASHIRAH: JOURNAL OF ISLAMIC STUIDES \\ Vol. 1 No. 1(2020): 160-179}

Website: https://journal.stiba.ac.id

ا معدم الدقة في العزو إلى من خرج الأحاديث، ولذا بتح الإمام الشوكاني يستدرك عليه فيقول:

$$
\text { وأخرجه غير المذكورين فلان وفلان. }
$$

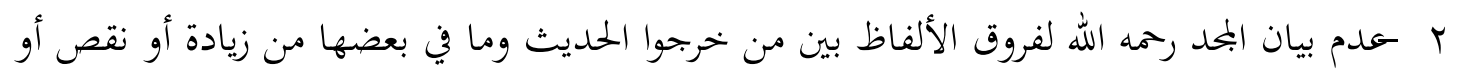

$$
\text { تفرد. }
$$

r معدم تعرض البمد رممه الله للكلام على التصحيح والتضعيف على ما ذكره من الأحاديث.

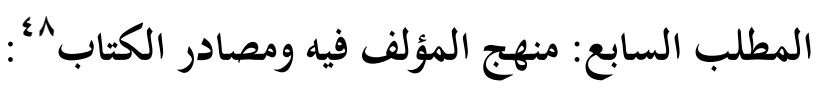

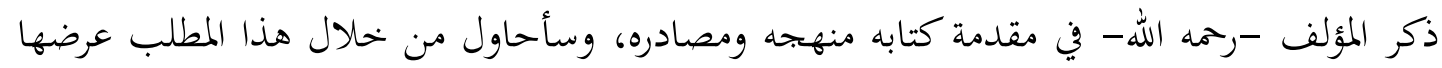

$$
\text { ملخصة في نقاط وأزيد بعض الأشياء المهمة التي لم يذكرها: }
$$

ذكر الإمام المجد ابن تيمية في مقدمة كتاب "المنتقى" ما يمكن أن نفهم منه منهجه في هذا الكتاب وقد

1

$$
\text { عليها علماء الإسلام. }
$$

r r r r الأحاديث في كتابه على ترتيب الفقهاء في زمانه فبدأ بكتاب الطهارة وانتهى بكتاب

$$
\text { الأقضية. }
$$

r متب كتب الفقه في كتابه إلى أبواب يترجم لها أحيانا ببعض ما دل عليه أحاديثها من الفوائد

$$
\text { والأحكام الفقهية. }
$$

$$
\text { ثانياً: مصادره: }
$$

1- انتقى أحاديث كتابه من صحيح البخاري ومسلم، ومسند أحمد، والسنن الأربعة، وسنن

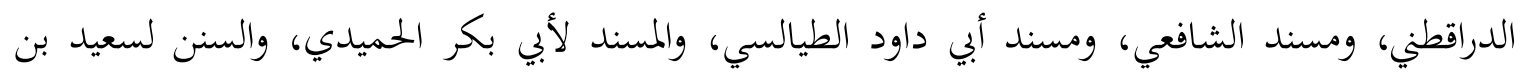
منصور، وغيرها.

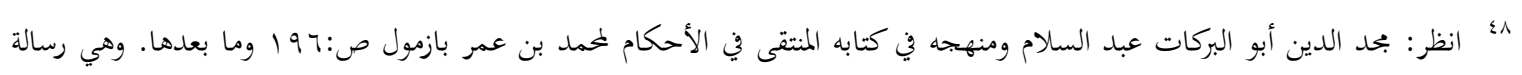

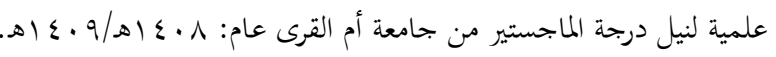
IV 


\section{البصسيرة: مبلة الصراهات الإهلاهية AL-BASHIRAH: JOURNAL OF ISLAMIC STUIDES \\ Vol. 1 No. 1(2020): 160-179}

Website: https://journal.stiba.ac.id

$$
\text { r- ونقل عن كتب غريب الحديث مثل: }
$$

غريب الحديث لأبي عبيد القاسم بن سلام، ولابن قتيبة، ولأبي إسحاق الحربي، ولأبئ ولأبي سليمان الخطابي.

$$
\begin{aligned}
& \text { r- نقل عن بعض شروحات الحديث مثل: } \\
& \text { أ- معالم السنن شرح سنن أبي داود للخطابي. } \\
& \text { ب- أعلام الحديث شرح البخاري للخطابي. } \\
& \text { ج-شرح السنة للبغوي. } \\
& \text { ع - ونقل من بعض كتب الفقه مثل: }
\end{aligned}
$$

أ- مسائل الإمام أحمد لأبي بكر الأحول، وأبي بكر المروذي، وحنبل بن إسحاق، وعبدالله بن الإمام

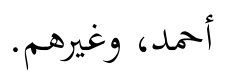

$$
\begin{aligned}
& \text { ب- الأموال لأبي عبيد القاسم بن سلام. } \\
& \text { ج- كتب ابن المنذر ككتاب السنن والإجماع. } \\
& \text { د- كتاب التحقيق في أحاديث الخلاف لابن الجوزي. }
\end{aligned}
$$

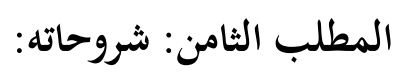

اعتنى العلماء قديما وحديثاً بكتاب منتقى الأخبار أيما اعتناء، فمنهم من أتمه، ومنهم من لم يتمه، وهذا

$$
\text { عرض لأهم وأشهر شروحه: }
$$

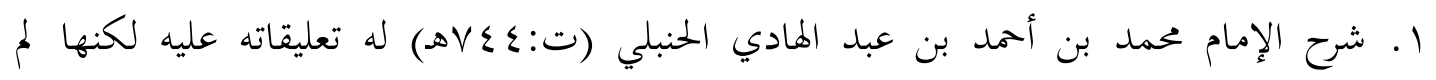

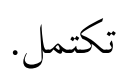

r. شرح الإمام سراج الدين عمر ابن الملقن الشافعي (ت:ــ •هه) لكنه لم يكمله بل كتب منه

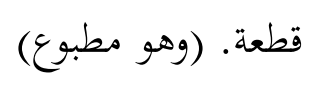

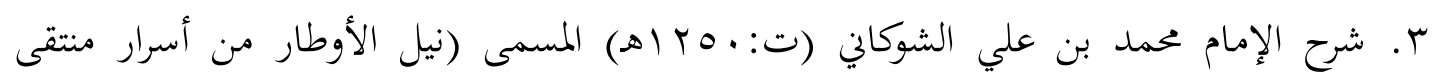

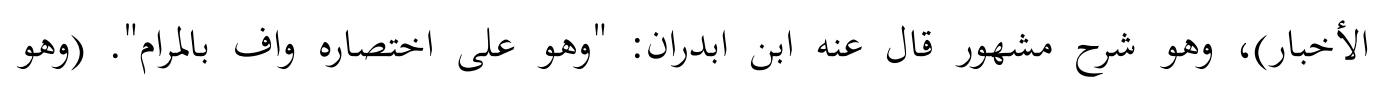

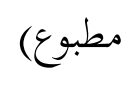

ع. بستان الأحبار اختصار نيل الأوطار للشيخ فيصل بن عبد العزيز آل مبارك (ت:عVI اهـ)، وهو 


\section{البصسيرة: مبلة الصراهات الإهلاهية AL-BASHIRAH: JOURNAL OF ISLAMIC STUIDES \\ Vol. 1 No. 1(2020): 160-179}

Website: https://journal.stiba.ac.id

اختصار لشرح الشوكاني السابق قال عنه مؤلفه في مقدمته: "واقتصرت على شرح ما يدل على

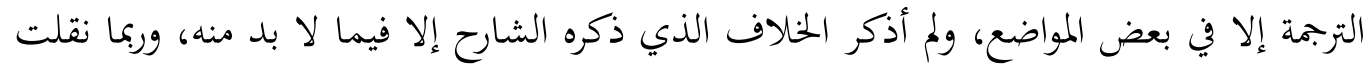

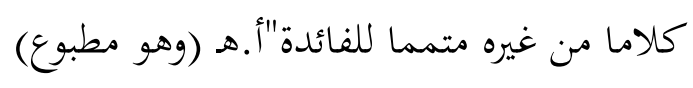

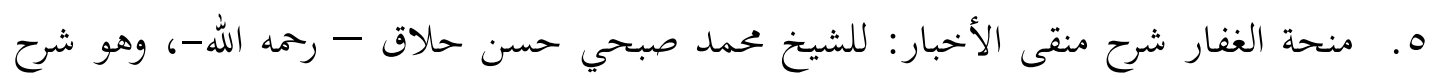

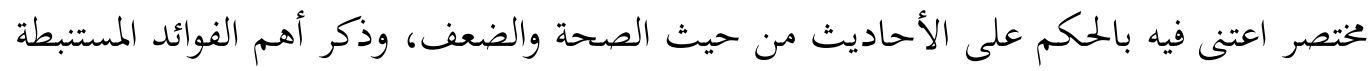

$$
\begin{aligned}
& \text { من الحديث مع بيان غريب الحديث. (وهو مطبوع) }
\end{aligned}
$$

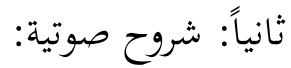

$$
\begin{aligned}
& \text { وهي كثيرة جدا، وغالبها غير مكتمل، ولعل من أهمها: }
\end{aligned}
$$

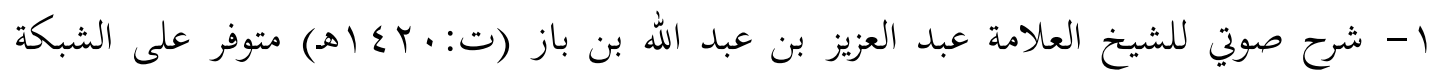

$$
\text { العنكبوتية، ولكنه لم يكتمل. [في ع ب شريط] }
$$

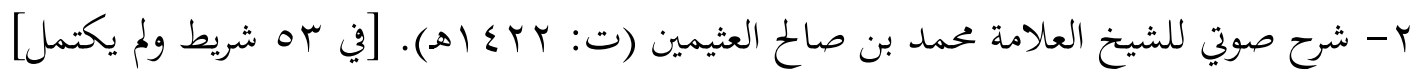

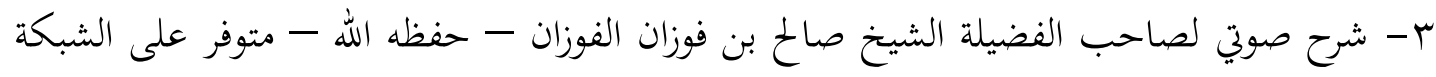
العنكبوتية، لكن لم يكتمل، وصدر منه المجلد الأول في شرح كتاب الطهارة.

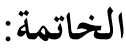

وبعد هذا التطواف حول علم من أعلام فقهاء الإسلام ومحدثيهم نصل إلى ختام هذا البحث الموجز، والذي

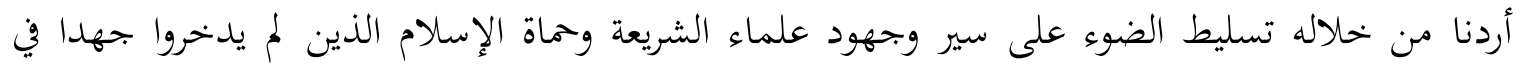

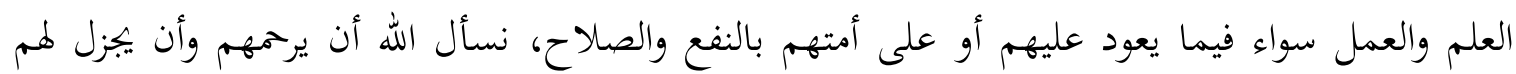
العطاء على ما قدموا وبذلوا، ويمكن أن نخرج في الختام ببعض المود النتائج لعل من أهمها:

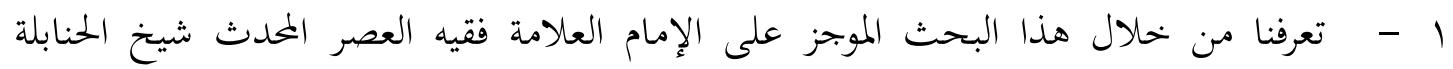

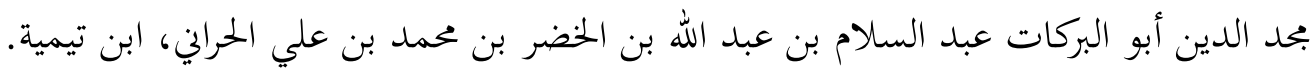

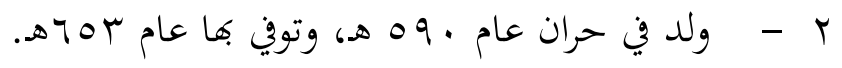

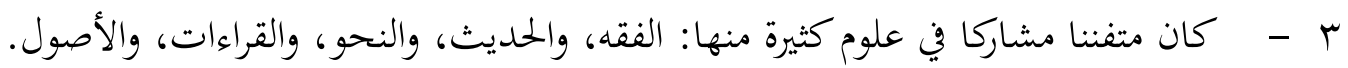

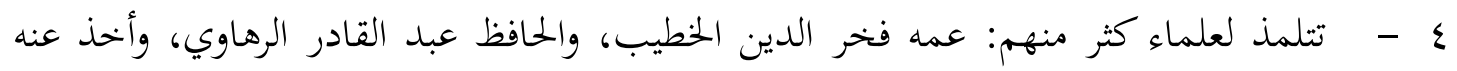




\section{البصيرة: مبلة الصراهات الإهلامية AL-BASHIRAH: JOURNAL OF ISLAMIC STUIDES \\ Vol. 1 No. 1(2020): 160-179}

Website: https://journal.stiba.ac.id

طلاب كثر منهم: نجم الدين أحمد بن حمدان، وأبو إسحاق بن الظاهري الحافظ.

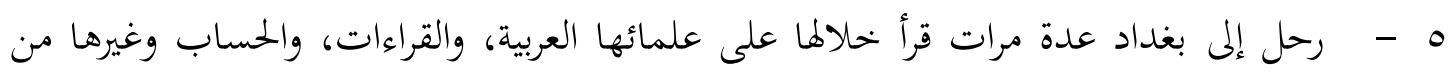

$$
\text { العلوم. }
$$

7

- V

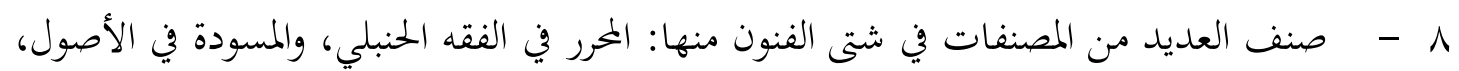

والمنتقى في الحديث، وأرجوزة في القراءات.

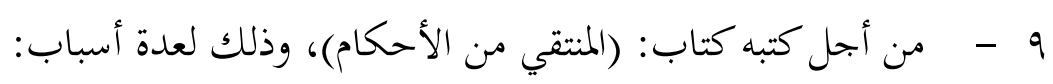

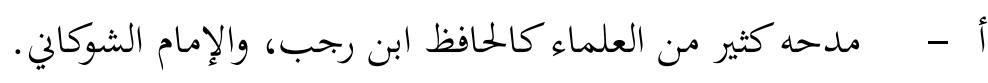

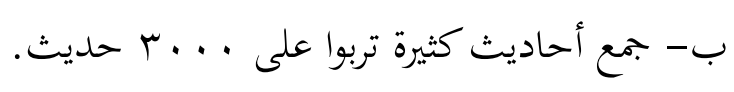

ج- اهتمام العلماء قديما وحديثا بشرحه.

• 1 - سبب تأليف الكتاب هو طلب القاضي بهاء الدين بن شداد من الإمام بحد الدين ذَلِكَ

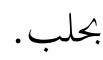

11 - الاسم الأصح للكتاب هو : ما اختاره الإمام الشوكاني شارح الكتاب وهي: (المنتقى من الأخبار في الأحكام).

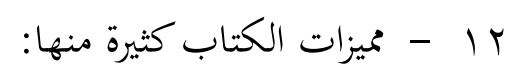

أ - ترتيب أحاديثه على أبواب كتب الفقه.

ب - ترتيب أبوابه ببعض ما دلت عليه أحاديثه من الفوائد.

rا 1 - من المؤاخذات على الكتاب -وهي قليلة -: عدم الدقة في عزو الألفاظ إلى مخرجيها.

ع ا - - نقل عن مصاد كثيرة منها الكتب الستة، ومعالم السنن للخطابي، والأموال لأبي عبيد.

$$
10
$$

أ - نيل الأوطار للإمام الشوكاني رحمه الله.

ب - شرح مسموع للعلامة عبد العزيز بن باز رحمه الله. 


\section{البصيرة: مبلة الصراهات الإهلامية AL-BASHIRAH: JOURNAL OF ISLAMIC STUIDES \\ Vol. 1 No. 1(2020): 160-179}

Website: https://journal.stiba.ac.id

والحمد لله أولا وآخرا وظاهرا وباطنا، وصلى الله على عبده ورسوله محمد، وعلى آله وصحبه وسلم.

\section{فهرس المصادر والمراجع}

أحمد بن علي بن حجر العسقلاني (ت: بـ10ه). بتحقيق: محمد عبد المعيد ضان. الدرر الكامنة

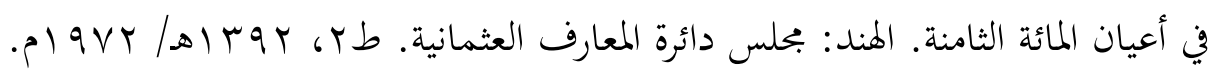

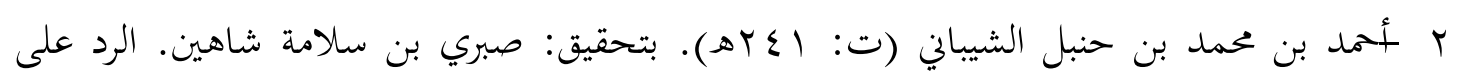

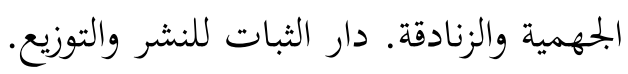

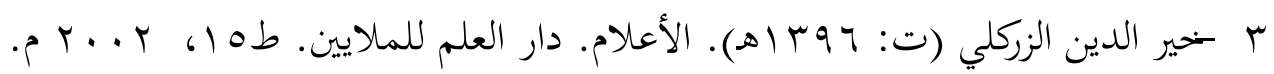

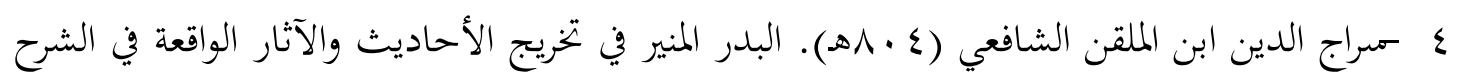

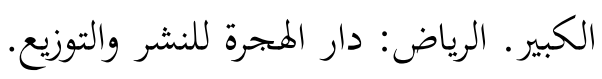

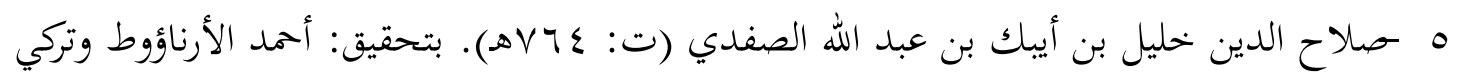

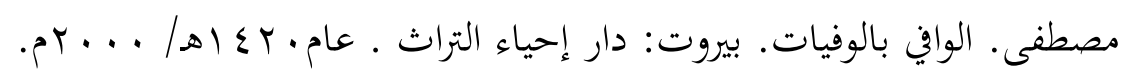

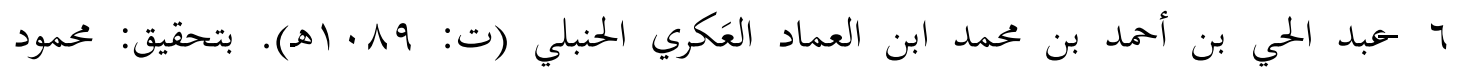

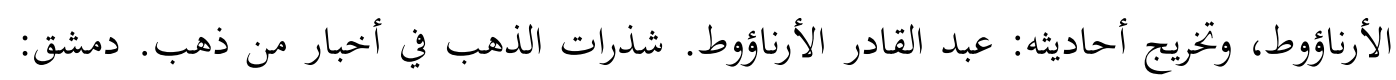

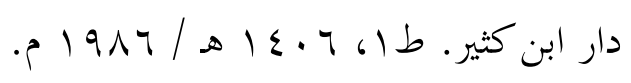

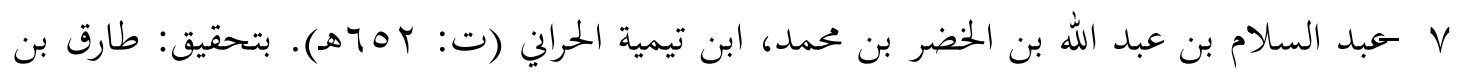

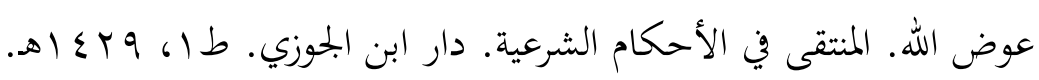

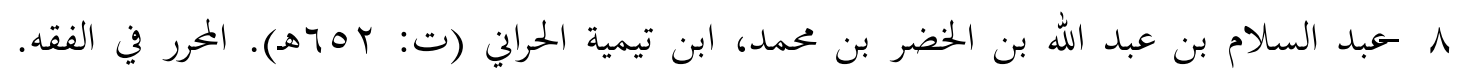

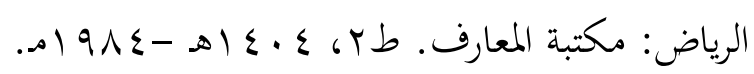

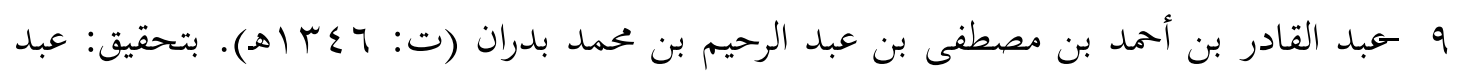

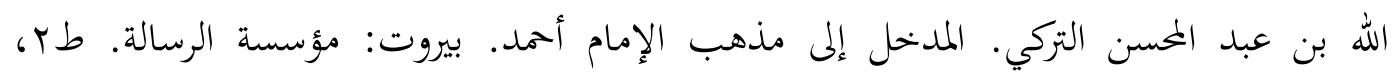
$.81 \leqslant \cdot 1$ • 1 - عمر رضاكحالة. معجم المؤلفين. بيروت: دار إحياء التراث العربي. 


\section{البصيرة: مبلة الصراهات الإهلامية AL-BASHIRAH: JOURNAL OF ISLAMIC STUIDES \\ Vol. 1 No. 1(2020): 160-179}

Website: https://journal.stiba.ac.id

11 - فيصل بن عبد العزيز بن فيصل ابن حمد المبارك الحريملي النجدي (ت: VIr اهـ). بستان

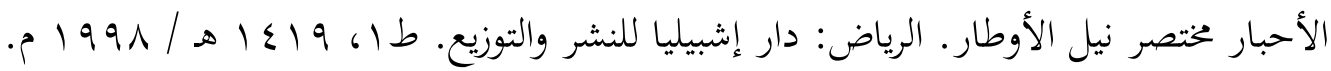

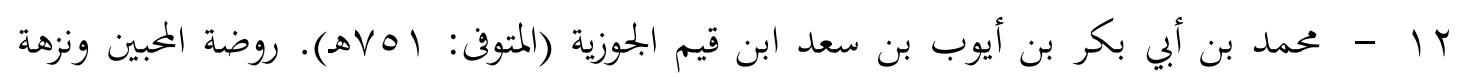

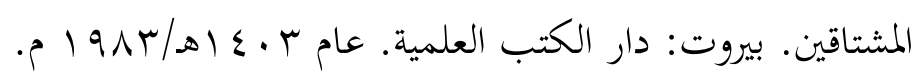

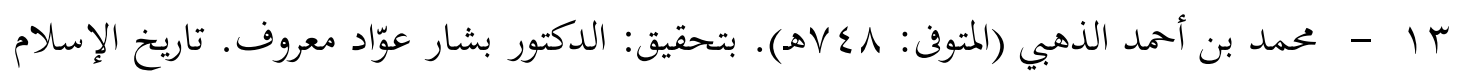

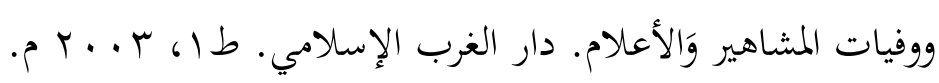

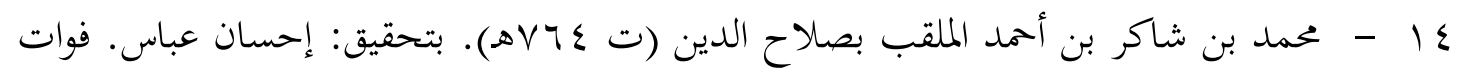

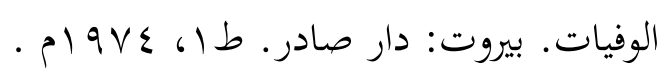

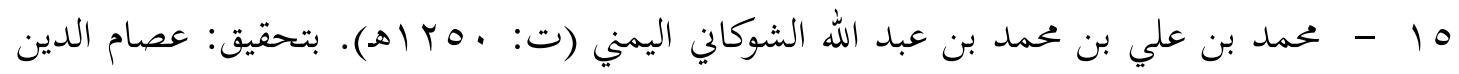

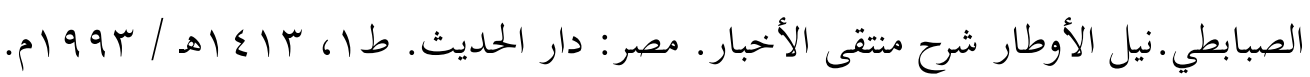

17

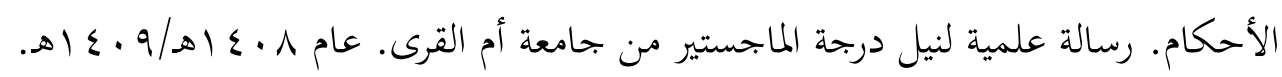

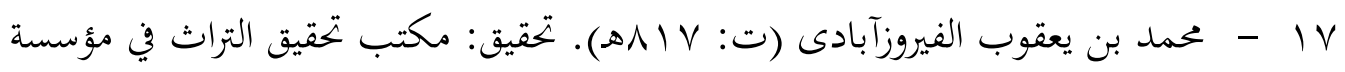

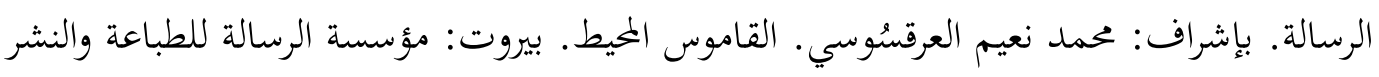

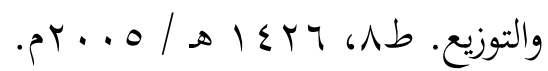

$$
\begin{aligned}
& \text { 11 - المواقع الإلكترونية: } \\
& 19
\end{aligned}
$$

https://www.ajurry.com/vb/

$$
\text { موقع ملتقى أهل الحديث - r. }
$$

/https://www.ahlalhdeeth.com 